\title{
Experimental and theoretical insight into electrocatalytic hydrogen evolution with nickel bis-aryldithiolene complexes as catalysts
}

\author{
Athanasios Zarkadoulas ${ }^{1}$, Martin J. Field ${ }^{2}$, Constantina Papatriantafyllopoulou ${ }^{3}$, Jennifer \\ Fize $^{4}$, Vincent Artero ${ }^{4,}$, and Christiana A. Mitsopoulou ${ }^{1,}$ \\ ${ }^{1}$ Inorganic Chemistry Laboratory, Chemistry Department, National and Kapodistrian University of \\ Athens, Panepistimiopolis, Zografou 157 71, Greece \\ ${ }^{2}$ DYNAMO/DYNAMOP, Institut de Biologie Structurale, UMR CNRS/Université Grenoble \\ Alpes/CEA 5075, EPN Campus, 6 rue Jules Horowitz F-38000 Grenoble, France \\ ${ }^{3}$ Department of Chemistry, University of Cyprus, 1678 Nicosia, Cyprus \\ ${ }^{4}$ Laboratory of Chemistry and Biology of Metals, Université Grenoble Alpes, CNRS, CEA, 17 rue \\ des Martyrs, F-38000 Grenoble, France
}

\section{Abstract}

\begin{abstract}
A series of neutral and monoanionic nickel dithiolene complexes with (p-methoxyphenyl)substituted 1,2-dithiolene ligands have been prepared and characterized with physicochemical methods. Two of the complexes - the monoanion of the symmetric $\left[\mathrm{Ni}\left\{\mathrm{S}_{2} \mathrm{C}_{2}-\left(-\mathrm{Ph}-\mathrm{p}-\mathrm{OCH}_{3}\right)_{2}\right\}_{2}\right]$ (3-) with $\mathrm{NBu}_{4}{ }^{+}$as a counter-ion and the neutral asymmetric $\left[\mathrm{Ni}\left\{\mathrm{S}_{2} \mathrm{C}_{2}(-\mathrm{Ph})\left(-\mathrm{Ph}-\mathrm{p}-\mathrm{OCH}_{3}\right)\right\}_{2}\right](2)-$ have been structurally characterized by single crystal X-ray crystallography. All complexes have been employed as proton reducing catalysts in DMF with trifluoroacetic acid as proton source. The complexes are active catalysts with good faradaic yields reaching $83 \%$ for $\mathbf{2}$ but relatively high overpotentials requirements $(0.91 \mathrm{~V}$ and $1.55 \mathrm{~V}$ measured at the middle of the catalytic wave for two processes observed depending on the different routes of the mechanism). The similarity of the experimental data regardless of whether the neutral or anionic form of the complexes is used indicates that the neutral form acts as pre-catalyst. On the basis of detailed DFT calculations the proposed mechanism reveals two main different routes after the protonation of the dianion of the catalyst in accordance with the experimental data, indicating the role of the concentration of the acid and the influence of the methoxy groups. Protonation at sulfur seems be more favorable than at the metal, which is in marked contrast with the catalytic mechanism proposed for analogous cobalt dithiolene complexes.
\end{abstract}

\section{Keywords}

dithiolene; nickel; electrocatalysis; DFT; non-innocent ligand; dithiolate; HER

Corresponding authors. Tel.: +30 2107274452 ; fax: +30 2107274435 (C.A. Mitsopoulou), cmitsop@ chem.uoa.gr (C.A. Mitsopoulou), vincent.artero@cea.fr (V. Artero). 


\section{Introduction}

The need for easily accessible renewable energy [1] has led to growth in the research field of artificial photosynthesis. In this context, water splitting can lead to evolution of hydrogen which can be used as a cheap, green fuel [2]. Hydrogen could also play an important role in the storage of energy obtained from diluted sources, such as solar and wind, via the conversion of electricity to chemical energy by electrolysis of water. Although the latter is a well-known technology, it has drawbacks, principally due to the use of noble metal catalysts, such as platinum. A challenging approach for overcoming this issue would be to develop novel, efficient and stable catalysts, that employ abundant, and as a consequence cheap, metals such as $\mathrm{Fe}, \mathrm{Co}, \mathrm{Ni}$ and $\mathrm{Cu}$. Based on this, researchers have synthesized various complexes of these metals as catalysts of the reductive side of the water splitting reaction, with reports of cobalt complexes, such as cobaloximes or macrocyclic and polypyridine cobalt complexes, being especially prevalent in the literature [3-6]. Recently a number of reviews on the activity of related complexes have appeared $[7,8,9]$.

In the last decade, many novel complexes have been designed that can be used as catalysts for $\mathrm{H}_{2}$ production. Bio-mimetic approaches, in which chemists take inspiration from catalysts that Nature uses, have been particularly fruitful. In the context of hydrogen production, the most appropriate bio-mimetic targets are the hydrogenases [10-13]. In the same vein, a ligand that has attractive properties is the dithiolene that is found in the active site of molybdopterin [14]. Metal dithiolenes have long been used in solar energy conversion applications, such as hydrogen evolution [15-17] and in dye-sensitized solar cells [18,19]. The non-innocent nature of the dithiolene ligand framework [20] allows construction of multi-functional complexes, since the reversible redox reactions that metal-dithiolene complexes undergo can be localized on the metal - leading to reduced metal oxidation states - or on the ligand, depending on the orbital contribution of each fragment [21]. The redox non-innocent character of dithiolene ligands is mainly based on their ability to reversible take up or release electrons yielding ene-dithiolate and dithioketone forms with distinct electronic structures and chemical properties, respectively (Scheme 1). Which one of these oxidation states is adopted depends on the substituents on the SCCS moiety of the dithiolene ligand and the nature of the metal. The term 1,2-dithiolene is a general term that describes the ligand framework and its use does not refer to a specific oxidation state on the metal or the ligand. Oxidation state and charge localization in metal dithiolene complexes has been the focus of extensive theoretical work [21,22] which has provided insight regarding chemical reactivity of dithiolene complexes [23] in various applications, including hydrogen evolution.

An initial report by Kisch [15] investigated photocatalytic hydrogen evolution with various dithiolene complexes. Several years later, Sellman et al reported on the mechanism of hydrogen evolution from the stoichiometric reaction of protons with an iron(II) bisdithiolene complex [24]. The redox events and hydrogen evolving activity of $\left[\mathrm{M}(\mathrm{mnt})_{2}\right]^{3-}$ $\left(\mathrm{M}=\mathrm{Rh}, \mathrm{Co}, \mathrm{Ni} ; \mathrm{mnt}^{2-}=\right.$ maleonitrile dithiolate ligand) complexes upon protonation has been reported by Vlček and Vlček [25], where the authors propose that protonation occurs at the metal centers. Tris-dithiolene complexes of molybdenum and tungsten were also used as 
water splitting catalysts $[14,16,26-28]$, although they proved to be unstable in the presence of metal ions that destroy the chelating dithiolene ring [29].

Interest in dithiolene complexes as hydrogen evolving catalysts has recently re-emerged, initially due to the group of Eisenberg and Holland, who reported a series of cobalt benzene-1,2-dithiolate ( bdt $^{2-}$ ) complexes that show promising performance with TONs of up to 9000 [30,31]. Based on experimental data, an ECEC mechanism was proposed for electrocatalytic hydrogen evolution. The mechanism included reduction of the monoanionic complex $\left[\mathrm{Co}(\mathrm{bdt})_{2}\right]^{-}$to the dianion, subsequent protonation of the dianion, reduction and a final protonation step leading to hydrogen evolution. Theoretical insight into the plausible mechanisms has been proposed by Solis et al. [32]. The first protonation was proposed to occur on a sulfur atom with the second protonation yielding a $\operatorname{Co}(\mathrm{I})$ hydride. A recent study by Letko et al. [33] reported the preparation and mechanism of electrocatalytic hydrogen evolution using cobalt anisyl complexes that bear different substituents on the benzene rings. Cyclic voltammetry indicated that reduction to the dianion precedes protonation, as in the aromatic dithiolene $\left(\mathrm{bdt}^{2-}\right)$ complexes studied by McNamara et al. [31]. Finally, a recent publication by the groups of Eisenberg and Holland [34] reported on the photocatalytic and electrocatalytic activity of a series of $\mathrm{Ni}$ complexes with benzene-1,2-dithiolene and related ligands that evolve hydrogen over a wide $\mathrm{pH}$ range and in different solvents and exhibit robustness under various experimental conditions.

Motivated by the above results, the knowledge that the electronic properties, and therefore the reactivity, of the dithiolene complexes are influenced by the substituents on the ditholene ligand, and the low cost and abundance of nickel in Nature, we have synthesized and characterized three nickel diphenyl-1,2-dithiolene complexes with varying numbers of methoxy groups on the benzene rings of the ligand framework. Structures are shown in Scheme 2. These complexes were tested for their catalytic properties regarding electroreduction of protons to $\mathrm{H}_{2}$ in DMF. Due to the electron donating effect of methoxy groups, fine tuning of reduction potentials can be achieved, since in this type of complex reduction is mainly localized on the ene-dithiolate fragment [35]. To the best of our knowledge, this is the first time that a systematic study has been performed of the structural and electronic changes that occur during proton reduction for this class of compounds. DFT calculations have also been employed for the elucidation of the reactive centers of the complexes and the structural conformations of the intermediates, from which putative reaction mechanisms are proposed.

\section{Experimental}

\section{General Considerations}

Reagents and solvents were purchased from Aldrich, Alfa Aesar, Merck or Fisher and used as received unless otherwise noted. Anisoin and 4-methoxybenzoin were prepared according to Sumrell et al. [36]. $\mathrm{CDCl}_{3}$ was distilled from $\mathrm{K}_{2} \mathrm{CO}_{3}$ and stored in the dark over $4 \mathrm{~A}$ molecular sieves.

IR spectra were recorded in $\mathrm{KBr}$ pellets with a $2.0 \mathrm{~cm}^{-1}$ resolution using a Shimadzu IR Affinity - 1. Elemental analyses were conducted using a LECO-183 CHNS analyzer. NMR 
spectra were recorded using a Varian Unity Plus instrument $(300 \mathrm{MHz})$ and spectra were corrected with the residual solvent peak as an internal standard. UV-Vis spectra were recorded with a Hitachi U-2000 and Varian Cary 3E spectrophotometer in $1.0 \mathrm{~cm}$ quartz cuvettes.

\section{Electrochemistry}

Electrochemical experiments were performed using an AFCBP1 Pine Instrument Company and Bio-Logic SP300 potentiostat. Cyclic voltammograms were recorded in a twocompartment cell with a glassy carbon working electrode, an $\mathrm{Ag} / \mathrm{AgCl}(\mathrm{KCl} 3 \mathrm{M})$ reference electrode and a platinum wire counter-electrode (located in the second compartment). The glassy carbon electrode was polished with diamond paste $(1 \mu \mathrm{m})$ or alumina $(1 \mu \mathrm{m})$ on a polishing cloth before each measurement. The solution was purged with argon or nitrogen gas prior to measurements. At the end of each experiment, sublimed ferrocene was added as an internal standard. Bulk electrolysis was performed in a two-compartment cell with a glassy carbon rod electrode ( $\varnothing 10 \mathrm{~mm}$, Neyco, Paris, France), an $\mathrm{Ag} / \mathrm{AgCl}$ reference electrode and a platinum wire as counter-electrode (located in the second compartment). The cell was continuously purged with nitrogen $\left(5 \mathrm{~mL} \cdot \mathrm{min}^{-1}\right)$ and the output gas was analyzed at two-minute intervals in a Perkin Elmer Clarus 500 gas chromatographer using a previously described setup [37]. All potentials in the text are reported versus $\mathrm{Fc}^{+/ 0}$ redox couple.

\section{X-rays structure determination}

Green-black crystals of $\mathbf{2}$ suitable for X-ray structure determination were grown from slow evaporation of a dichloromethane - heptane solution of the complex. Red crystals of $\mathbf{3}^{-}$were grown by layering a dichloromethane solution of the complex with n-hexane. Data were collected on a SuperNova A Oxford Diffraction diffractometer, equipped with a CCD area detector and a graphite monochromator utilizing Mo-Ka radiation $\left(\lambda=0.71073 \AA\right.$ ) for $3^{-}$, and $\mathrm{Cu}-\mathrm{Ka}$ radiation $(\lambda=1.54184 \AA$ ) for 2 . Suitable crystals covered with paratone-N oil were mounted on the tip of glass fibers or scooped up in cryo-loops at the end of a copper pin and transferred to a goniostat where they were cooled for data collection. Empirical absorption corrections (multi-scan based on symmetry-related measurements) were applied using CrysAlis RED software [38]. The structures were solved by direct methods with SIR92 [39] and refined on $F^{2}$ using full-matrix least squares with SHELXL97 [40]. Software packages used: CrysAlis CCD for data collection [38], CrysAlis RED for cell refinement and data reduction [38], WINGX for geometric calculations [41], and MERCURY [42]for molecular graphics. The non-H atoms were treated anisotropically, whereas the hydrogen atoms were placed in calculated, ideal positions and refined as riding on their respective carbon atoms. Unit cell data and structure refinement details for compounds $\mathbf{2}$ and $\mathbf{3}^{-}$are listed in Table 1. Full details can be found in the CIF files provided in Supplementary Information.

\section{DFT studies}

All quantum chemical calculations were done with a density functional theory (DFT) approach using the B3LYP functional and basis sets of triple-zeta (TZVP) quality. The ORCA program package (version 2.9.1) was employed for all electronic structure 
calculations [43]. Two approaches were employed for estimating the relative energies of different species and the energies of the various reactions. In the first, geometry optimizations were performed for all species in vacuum using the B3LYP functional and a TZVP basis set. Single point energy calculations were then performed on these optimized vacuum structures using the B3LYP functional and an extended TZVP basis set with extra polarization and diffuse functions. These single point calculations were performed in both vacuum and DMF solvent using the COSMO implicit solvation method that ORCA implements [44]. In addition, normal mode calculations were performed at the vacuum optimized geometries using the B3LYP functional and original TZVP basis set to obtain the appropriate free energy contributions to the species energies. The latter were estimated as the sum of the single point vacuum energy, the solvation energy (the difference between the single point solvent and vacuum energies) and the free energy contribution from the normal mode calculations. This approach seems to be similar to that used by many workers, including that described in Konezny and co-workers [45]. In the second approach performed as a check of the first - potential (rather than free) energies for the reactions were estimated by geometry optimizing all species in DMF solvent using the B3LYP functional and a TZVP basis set, followed by single point calculations in DMF solvent with the same functional and the larger TZVP basis set.

\section{Preparation of the neutral compounds}

1, 2 and 3 were prepared using the benzoin $/ \mathrm{P}_{4} \mathrm{~S}_{10}$ method of Schrauzer as modified by Bui et al. [46] with yields reaching 30\%. Analytical data for these complexes are as follows:

1: $\quad{ }^{1} \mathrm{H}-\mathrm{NMR}$ in $\mathrm{CDCl}_{3}: 7.31-7.41 \mathrm{ppm}\left(\mathrm{m}, 20 \mathrm{H}\right.$, aromatic); IR: $1363 \mathrm{~cm}^{-1}\left(\mathrm{~s}, \bar{V}_{\mathrm{C}=\mathrm{C}}\right)$, $1140 \mathrm{~cm}^{-1}$ (s, ${\overline{V_{C}}}_{\mathrm{S}}), 882 \mathrm{~cm}^{-1}$ (s, $\overline{\mathrm{V}}_{\mathrm{C}-\mathrm{S}}$ ); UV-Vis: DMF (860 nm, 29200 $\mathrm{M}^{-1} \mathrm{~cm}^{-1}$ ). Anal. calcd for $\mathrm{C}_{28} \mathrm{H}_{20} \mathrm{NiS}_{4}$ : C: 61.89 , H: 3.71, S: 23.60; found: C: 61.92, H: 3.80, S: 23.44.

2: $\quad{ }^{1} \mathrm{H}-\mathrm{NMR}$ in $\mathrm{CDCl}_{3}: 3.83 \mathrm{ppm}(\mathrm{s}, 6 \mathrm{H}, \mathrm{OMe}), 6.81 \mathrm{ppm}(\mathrm{d}, 4 \mathrm{H}, \mathrm{p}$-substituted phenyl ring), $7.39 \mathrm{ppm}$ (m, 14H, aromatic); IR: $1357 \mathrm{~cm}^{-1}$ (s, $\left.\overline{\mathrm{V}}_{\mathrm{C}=\mathrm{C}}\right), 1254 \mathrm{~cm}^{-1}$ (s, $\bar{V}_{\mathrm{C}-\mathrm{OMe}}$ ), $1144 \mathrm{~cm}^{-1}$ (s, $\left.\overline{\mathrm{V}}_{\mathrm{C}-\mathrm{S}}\right), 886 \mathrm{~cm}^{-1}$ (s, $\overline{\mathrm{V}}_{\mathrm{C}-\mathrm{S}}$ ); UV-Vis: DMF $(902 \mathrm{~nm}$, $32100 \mathrm{M}^{-1} \mathrm{~cm}^{-1}$ ). Anal. calcd for $\mathrm{C}_{30} \mathrm{H}_{24} \mathrm{NiO}_{2} \mathrm{~S}_{4}$ : C: 59.71, H: 4.01, S: 21.25; found: C: 59.58, H: 4.12, S: 21.17 .

3: $\quad{ }^{1} \mathrm{H}-\mathrm{NMR}$ in $\mathrm{CDCl}_{3}: 3.86 \mathrm{ppm}(\mathrm{s}, 12 \mathrm{H}, \mathrm{OMe}), 6.85 \mathrm{ppm}(\mathrm{d}, 8 \mathrm{H}, \mathrm{p}$-substituted phenyl ring), $7.38 \mathrm{ppm}\left(\mathrm{d}, 8 \mathrm{H}\right.$, aromatic); IR: $1350 \mathrm{~cm}^{-1}\left(\mathrm{~s}, \bar{V}_{\mathrm{C}=\mathrm{C}}\right), 1249 \mathrm{~cm}^{-1}$ (s, ${\overline{V_{\mathrm{C}}-\mathrm{OMe}}}$ ), $1143 \mathrm{~cm}^{-1}$ (s, $\overline{\mathrm{V}}_{\mathrm{C}-\mathrm{S}}$ ), $887 \mathrm{~cm}^{-1}$ (s, $\overline{\mathrm{V}}_{\mathrm{C}-\mathrm{S}}$ ); UV-Vis: DMF (934 nm, 30600 $\mathrm{M}^{-1} \mathrm{~cm}^{-1}$ ). Anal. calcd for $\mathrm{C}_{32} \mathrm{H}_{28} \mathrm{NiO}_{4} \mathrm{~S}_{4}$ : C: 57.93 , H: 4.25, S: 19.33; found: C: 57.81, H: 4.38, S: 19.39 .

\section{Preparation of the anionic complexes $1^{-}, 2^{-}$and $3^{-}$}

$0.1 \mathrm{mmol}$ of each neutral complex was suspended in a 1:1 mixture of dichloromethane and methanol (30 mL total volume). 1.1 eq. of powdered $\mathrm{NaBH}_{4}$ was added under stirring and the green-black suspension gradually turned into a red-brown effervescent solution. The solution was stirred for 10 min until gas evolution ceased and then 1 eq. of tetra-nbutylammonium bromide was added as a solid. The resulting suspension was stirred for 10 
minutes, filtered using a sintered funnel and washed with copious amounts of warm water, methanol and ether. The resulting solids were dried under vacuum overnight. Yields were quantitative. The anionic compounds are paramagnetic and thus no NMR spectra were recorded.

1': IR: $1455 \mathrm{~cm}^{-1}\left(\mathrm{~s}, \bar{V}_{\mathrm{C}=\mathrm{C}}\right), 1177 \mathrm{~cm}^{-1}\left(\mathrm{~s}, \bar{V}_{\mathrm{C}-\mathrm{S}}\right), 867 \mathrm{~cm}^{-1}\left(\mathrm{~s}, \bar{V}_{\mathrm{C}-\mathrm{S}}\right)$; UV-Vis: DMF $\left(938 \mathrm{~nm}, 13900 \mathrm{M}^{-1} \mathrm{~cm}^{-1}\right)$. Anal. calcd for $\mathrm{C}_{44} \mathrm{H}_{56} \mathrm{NNiS}_{4}$ : C: 67.25, H: 7.18, N: 1.78, S: 16.32; found: C: 67.18, H: 7.24, N: 1.69, S: 16.41 .

2-: $\quad$ IR: $1453 \mathrm{~cm}^{-1}\left(\mathrm{~s},{\overline{V_{\mathrm{C}}}}_{\mathrm{C}}\right), 1239 \mathrm{~cm}^{-1}\left(\mathrm{~s},{\overline{V_{\mathrm{C}}-\mathrm{OMe}}}_{\mathrm{e}}\right), 1175 \mathrm{~cm}^{-1}\left(\mathrm{~s}, \overline{\mathrm{V}}_{\mathrm{C}-\mathrm{S}}\right), 844 \mathrm{~cm}^{-1}$ (s, $\overline{\mathrm{V}}_{\mathrm{C}-\mathrm{S}}$ ); UV-Vis: DMF $\left(953 \mathrm{~nm}, 15200 \mathrm{M}^{-1} \mathrm{~cm}^{-1}\right)$. Anal. calcd for $\mathrm{C}_{46} \mathrm{H}_{60} \mathrm{NNiO}_{2} \mathrm{~S}_{4}$ : C: 65.31, H: 7.15, N: 1.66, S: 15.16; found: C: 65.26, H: 7.07, $\mathrm{N}: 1.75, \mathrm{~S}: 15.02$.

3- $\quad$ IR: $1450 \mathrm{~cm}^{-1}\left(\mathrm{~s}, \bar{V}_{\mathrm{C}=\mathrm{C}}\right), 1244 \mathrm{~cm}^{-1}\left(\mathrm{~s},{\overline{V_{\mathrm{C}}-\mathrm{OMe}}}_{\mathrm{e}}\right), 1174 \mathrm{~cm}^{-1}\left(\mathrm{~s}, \overline{\mathrm{V}}_{\mathrm{C}-\mathrm{S}}\right), 874 \mathrm{~cm}^{-1}$ (s, $\overline{\mathrm{V}}_{\mathrm{C}-\mathrm{S}}$ ); UV-Vis: DMF $\left(967 \mathrm{~nm}, 10000 \mathrm{M}^{-1} \mathrm{~cm}^{-1}\right)$. Anal. calcd for $\mathrm{C}_{48} \mathrm{H}_{64} \mathrm{NNiO}_{4} \mathrm{~S}_{4}: \mathrm{C}: 63.63, \mathrm{H}: 7.12, \mathrm{~N}: 1.55$, S: 14.16; found: C: 63.72, H: 7.20, $\mathrm{N}: 1.63, \mathrm{~S}: 14.20$.

\section{Results and discussion}

\section{Synthesis of the complexes}

The three nickel dithiolene complexes under study were prepared using literature procedures, more specifically using the benzoin/ $\mathrm{P}_{4} \mathrm{~S}_{10}$ method where a benzoin is reacted with an excess of phosphorus (V) sulfide in refluxing dioxane to yield the intermediate thiophosphoric ester which reacts with nickel(II) chloride in a dioxane - water mixture. Although more efficient methods to prepare the complexes have been proposed in the literature, such as the use of 1,3-dithiol-2-ones [47,48] or alkylated phosphorus intermediates [49], the benzoin method has been applied because of its simplicity and the availability of starting benzoins.

The anionic complexes were prepared using sodium borohydride as a mild reducing agent and precipitated with tetra-n-butylammonium bromide. Alkylammonium salts with shorter carbon chains (e.g. tetraethylammonium) can be used but the resulting compounds are less soluble in non-polar solvents.

\section{UV-Vis spectroscopy}

All complexes exhibit absorption spectra similar to those reported earlier for similar Ni-bisdithiolene complexes [50]. Normalized absorption spectra in DMF for neutral and monoanionic complexes are shown in Figure 1. The spectra for the neutral complexes exhibit two major bands around $600 \mathrm{~nm}$ and $900 \mathrm{~nm}$, the latter being described as $\pi-\pi^{*}$ transitions of the dithiolene ligand [51,52]. For $\mathbf{1}, \mathbf{2}$ and $\mathbf{3}$ the prominent band is observed at $860 \mathrm{~nm}, 902 \mathrm{~nm}$ and $934 \mathrm{~nm}$, respectively, with molar absorptivity values of 29200, 32100 and $30600 \mathrm{M}^{-1} \mathrm{~cm}^{-1}$. Increasing methoxy subtitution induces a $30-40 \mathrm{~nm}$ bathochromic shift in the nIR band, since the increasing electron-donating effect of additional methoxy groups decreases the HOMO-LUMO energy gap of the complex, as reported for similar compounds $[51,53]$. 
This trend is also observed in the monoanionic complexes, where the nIR band bathochromic shifts compared to the corresponding neutral complexes and is located at 938 , 953 and $967 \mathrm{~nm}$ for $\mathbf{1}^{-}, \mathbf{2}^{-}, \mathbf{3}^{-}$, respectively, with molar absorptivity values almost half-those of the neutral complexes, namely $13900\left(\mathbf{1}^{-}\right), 15200\left(\mathbf{2}^{-}\right)$and $10000\left(\mathbf{3}^{-}\right) \mathrm{M}^{-1} \mathrm{~cm}^{-1}$.

\section{Vibrational spectroscopy}

The complexes exhibit IR spectra typical of similar complexes [54,55]. For the neutral complexes 1, 2 and $3 \bar{V}(\mathrm{C}-\mathrm{C})$ values are in the region of $1350-1360 \mathrm{~cm}^{-1}$, with a decrease in wavenumber value as the number of methoxy groups increases. In all methoxy-substituted complexes $\left(\mathbf{2}, \mathbf{3}, \mathbf{2}^{-}, \mathbf{3}^{-}\right)$a band corresponding to the aryl - OMe vibration is observed around $1250 \mathrm{~cm}^{-1}$ for the neutral and $1240 \mathrm{~cm}^{-1}$ for the anionic complexes. This band is absent in the case of unsubstituted compounds 1 and $\mathbf{1}^{-}$. The $\bar{v}(\mathrm{C}-\mathrm{S})$ values are observed in the region of $\sim 880 \mathrm{~cm}^{-1}$ and follow the opposite trend compared to the $\bar{V}(\mathrm{C}-\mathrm{C})$ values. Examination of the spectra of the anionic complexes leads to the observation that upon reduction the $\bar{v}(\mathrm{C}-\mathrm{C})$ values increase and the $\bar{v}(\mathrm{C}-\mathrm{S})$ values decrease, which is attributed to the fact that in the reduced complexes the ligands possess ene-dithiolate character (Scheme 1) [55].

\section{Structural analysis}

Single crystals suitable for structure determination were isolated for complexes $\mathbf{2}$ and $\mathbf{3}^{-}$ (Figures 2 and 3) and selected bond distances are presented in Table 2. Complex $\mathbf{3}^{-}$was isolated as tetrabutylammonium salt.

To the best of our knowledge, $\mathbf{2}$ is the first example of an asymmetric phenyl-substituted bisdithiolene complex to be structurally characterized. The neutral form of $\mathbf{3}^{-}$, i.e. $\mathbf{3}$, has been reported earlier by Arumugam et al. [49]. The structure of the complexes is representative for the Ni-bis-dithiolene system, with an almost perfectly planar configuration of the $\mathrm{NiS}_{4}$ core for both complexes. Bond lengths $(\mathrm{Ni}-\mathrm{S}, \mathrm{C}-\mathrm{S}, \mathrm{C}-\mathrm{C})$ are comparable to those reported for analogous complexes, with the average $\mathrm{Ni}-\mathrm{S}$ bonds in the literature [56] being $2.101-2.223 \AA$, the $\mathrm{S}-\mathrm{C}$ bonds $1.642-1.777 \AA$ and $\mathrm{C}-\mathrm{C} 1.284-1.520 \AA$.

It is of interest to compare how addition of methoxy groups affects the bond lengths of complexes 1,2 and $3 . \mathrm{Ni}-\mathrm{S}$ and $\mathrm{C}-\mathrm{S}$ bonds remain practically unaffected but $\mathrm{C} 1-\mathrm{C} 2$ and $\mathrm{C} 16-\mathrm{C} 17$ bonds vary notably. In complex 1 the $\mathrm{C}-\mathrm{C}$ bond distance of the dithiol-ene moiety $(\mathrm{C} 1-\mathrm{C} 2$ and $\mathrm{C} 16-\mathrm{C} 17)$ is $\sim 1.388 \AA$, and addition of one methoxy group leads to a significant elongation of the same bonds (1.423 and $1.402 \AA$ ). However, addition of one more methoxy group to the remaining phenyl ring leads to intermediate bond lenghts (1.394 and $1.391 \AA$ ), so in terms of the $\mathrm{C}-\mathrm{C}_{\mathrm{ene}}$ bond length the trend is $\mathbf{1}<\mathbf{3}<\mathbf{2}$. The noninnocence of the dithiolene ligands in neutral Ni-bis-dithiolene complexes 1-3 involves coordination of two radical anionic ligands to a $\mathrm{Ni}$ (II) ion [22]. The radical anionic nature of the coordinated dithiolene ligand is well depicted by the two extreme resonant forms A and B in Scheme 3 where for simplicity only one of the coordinated ligands is depicted, with one sulfur atom with radical anion character and the other one engaged in a thioketone function. The form $\mathrm{C}$ depicts the delocalized nature of the coordinated ligand as a sum of forms $\mathrm{A}$ and $\mathrm{B}$, where electron density is distributed over the five-atom $\mathrm{NiS}_{2} \mathrm{C}_{2}$ ring. 
When $\mathrm{R}=\mathrm{R}$, the negative charge is delocalized in a symmetrical manner over the SCCS core (form C). Actually, this is also supported from the aforementioned trend for $\mathrm{C}-\mathrm{C}_{\mathrm{ene}}$ bond length, indicating that the two symmetric complexes $\mathbf{1}$ and $\mathbf{3}$ adopt a structure where the charge is evenly distributed over the $\mathrm{NiS}_{2} \mathrm{C}_{2}$ core (form C, Scheme 3). Moreover, it has been proved by $\mathrm{S}$ K-edge XAS data combined with theoretical calculations that if the contribution of the metal $\mathrm{d}_{\mathrm{xz}}$ orbital dials up to $25 \%$ then 0.4 of an electron spin is located in each ligand with the metal orbital to act as a superexchange pathway between the two partially spin polarized ligands [19]. When $\mathrm{R} \neq \mathrm{R}$ ' as in our case for complex $\mathbf{2}(\mathrm{R}=$ phenyl, $\mathrm{R}^{\prime}$ = 4-methoxyphenyl), one of the first two resonance forms must contribute more to the bonding scheme. While differences in $\mathrm{C}-\mathrm{S}$ and $\mathrm{Ni}-\mathrm{S}$ bond lengths are within experimental error, the $\mathrm{C}-\mathrm{C}$ bonds provide insight into the electronic structure of $\mathbf{2}$. As mentioned earlier, 2 exhibits elongated $\mathrm{C} 1-\mathrm{C} 2$ and $\mathrm{C} 16-\mathrm{C} 17$ bonds, an indication that in 2 the $\mathrm{C}-\mathrm{C}$ bond resembles a single bond. Thus, one of the two first structures (forms $\mathrm{A}$ and B) of Scheme 3 describes better the structure of 2 . The DFT calculations (vide infra) indicate that protonation occurs at the sulfur atom which is in proximity to the 4methoxyphenyl group of $\mathbf{2}$. Based on the fact that the thiolate sulfur atom is richer in electron density than the thioketone sulfur atom, which facilitates protonation, we propose that the bonding scheme in catalyst $\mathbf{2}$ is best described by form B ( $\mathrm{R}=$, phenyl $\mathrm{R}^{\prime}=4$ methoxyphenyl) of Scheme 3.

Comparison between the neutral and monoanionic complexes $\mathbf{3}$ and $\mathbf{3}^{-}$at first reveals shortening of $\mathrm{C} 1-\mathrm{C} 2$ and $\mathrm{C} 16-\mathrm{C} 17$ bonds with a concomitant elongation of $\mathrm{C}-\mathrm{S}$ and $\mathrm{Ni}$ $-\mathrm{S}$ bonds. This trend has been observed for the $\left[\mathrm{Ni}\left(\mathrm{S}_{2} \mathrm{C}_{2} \mathrm{Me}_{2}\right)_{2}\right]^{0 /-1 /-2}$ series in a detailed study by Lim et al. [57]. DFT and vibrational data indicate that the reduction is a ligandbased event and leads to electronic saturation of the ligand, with the dianionic extreme being better described as two dianionic ene-dithiolate ligands coordinated to a $\mathrm{Ni}$ (II) ion. Thus, shortening of $\mathrm{C}-\mathrm{C}$ bonds is anticipated as these bonds acquire a double bond character, which is further corroborated by the increased wavenumber values observed in the IR spectra for the vibration of $\mathrm{C}-\mathrm{C}$ bonds. Elongation of $\mathrm{C}-\mathrm{S}$ bonds is attributed to the loss of dithioketone character upon reduction.

\section{Electrochemistry}

The electrochemical behavior of all complexes was investigated with cyclic voltammetry in DMF in the presence of $\mathrm{nBu}_{4} \mathrm{NPF}_{6}(0.1 \mathrm{M})$ as supporting electrolyte. Examination of either the monoanionic or neutral compounds revealed the same behavior so only the electrochemical characteristics of the neutral compounds are reported here. Two welldefined reversible redox events are observed, corresponding to the one- and two-electron reductions of complexes 1-3 as documented in the literature for compound 1 [58]. Introduction of methoxy groups on the phenyl rings has an effect on reduction potential, since the methoxy electron-donating groups lead to increased electron density on the sulfur atoms. A trend can be observed where the most difficult complex to reduce is $\mathbf{3}$ and the easiest to reduce is $\mathbf{1}$ (Table 3). Reduction potential values are in the range of -0.274 to $-0.370 \mathrm{~V} \mathrm{vs} \mathrm{Fc} c^{+/ 0}$ for the first reduction to the monoanion (0/-1 process) and -1.260 to -1.325 $\mathrm{V}$ vs $\mathrm{Fc}^{+/ 0}$ for the second reduction to the dianion (-1/-2 process). Although the behavior is similar to the respective cobalt compound [33], the reductions of $\mathbf{3}$ are found at less negative 
potential values than the cobalt analogue complexes. Normalized cyclic voltammogramms are shown in Figure 4 and reduction potentials can be found in Table 3.

\section{Electrocatalytic proton reduction}

Trifluoroacetic acid (TFA, pKa $=6.0$ in DMF [59]) has been employed as the proton source in hydrogen evolution experiments. Addition of TFA aliquots to solutions of catalyst $\mathbf{1}, \mathbf{2}$ or 3 in DMF triggers the appearance of catalytic waves that grow at potentials significantly more cathodic than that of the reversible redox potential corresponding to the formation of the dianionic species. For complex 1, two catalytic processes are observed at approximately $-1.75 \mathrm{~V}$ and $-1.9 \mathrm{~V}$ vs $\mathrm{Fc}^{+/ 0}$ (mid-wave potentials, see Figure 5) measured at the middle of the catalytic waves for $5 \mathrm{mM}$ TFA concentration. Direct reduction of TFA at the glassy carbon electrode occurs at potentials more negative than $-2.2 \mathrm{~V} \mathrm{vs} \mathrm{Fc}^{+/ 0}$ (Figure S3). We can therefore conclude that both catalytic waves are mediated by the nickel-based catalysts. For comparison, similar Co- and Ni-dithiolene complexes (with maleonitrile-dithiolate or 1,2benzene-dithiolate ligands) exhibit only one wave in the presence of organic acids $[30,31,61]$.

As the acid concentration increases and reaches $10 \mathrm{mM}$, the process with a half-wave potential of $-1.75 \mathrm{~V}$ saturates and the process with half-wave potential of $-1.9 \mathrm{~V}$ prevails. The equilibrium potential for the reduction of TFA $(5 \mathrm{mM})$ into $\mathrm{H}_{2}$ in DMF is $-0.94 \mathrm{~V}$ vs $\mathrm{Fc}^{+/ 0}$, was calculated using the method described in references $[59,62]$ (see supplementary information, equation S1). This value allows overpotential requirement of $0.81 \mathrm{~V}$ and $0.96 \mathrm{~V}$ to be determined at the mid wave potentials for the two above mentioned processes, respectively. The aforementioned trend is followed by complexes $\mathbf{2}$ and $\mathbf{3}$ (Figures S1 and S2) with similar overpotential requirements.

At the same time, there is a concomitant loss of the reversibility of the $-1 /-2$ redox process, indicating that a fast chemical reaction, likely protonation, takes place after reduction to the dianion. This is in accordance with the fact that the sulfur atoms which act as intramolecular proton relays/protonation sites, are nucleophilic enough for protonation to occur only when the complex is fully reduced $[33,63]$. The peak potential of the cathodic wave $\left(\mathrm{E}_{\mathrm{p}}\right)$ moves towards more positive potentials with increasing amounts of protons, as expected for such an EC process (equation 1) [64]. Plotting $E_{p}$ as a function of $\log$ [TFA] for catalysts $\mathbf{1 ,} 2$ and $\mathbf{3}$ results in linear relationships between these two quantities (Figure S4) with slopes of 37.5, 47.6 and $50.5 \mathrm{mV}$ per $\log$ unit respectively. Protonation constant $\left(k_{\mathrm{H}+}\right)$ values of $1.78 \times 10^{5}$, $3.51 \times 10^{7}$ and $4.31 \times 10^{7} \mathrm{~s}^{-1}$ could then be determined using equation 1 for the initial protonation step following the $-1 /-2$ reduction process $[65,66]$.

$$
E_{p}=E^{0}-0.78 \frac{R T}{F}+\frac{R T \ln 10}{2 F} \log \left(\frac{R T k_{H}+[T F A]}{F \nu}\right) \quad \text { Equation } 1
$$

However, the current enhancement observed at the -1/-2 cathodic peak for catalysts 1-3 (53, 41 and 53\%, respectively; Figure 5, S1 and S2) in the presence of $10 \mathrm{mM}$ TFA is larger than the $\sim 11 \%$ increase of the peak current expected for an EC process [66], suggesting that a catalytic process might also occur at this potential value. 
Production of $\mathrm{H}_{2}$ was confirmed using controlled potential bulk electrolysis in DMF at -1.67 $\mathrm{V}$ vs $\mathrm{Fc}^{+/ 0}$, corresponding to the onset potential of the first catalytic wave mentioned above. The concentrations of the catalyst and TFA were 1 and $50 \mathrm{mM}$, respectively. Bulk electrolysis was performed for $3 \mathrm{~h}$ using a glassy carbon rod electrode and the evolved hydrogen was quantified by gas chromatography. A faradaic yield of 66 to $83 \%$ is observed for all three complexes with the highest value for the asymmetric complex 2. Complex 2 also performs best with a TON of 25, compared to 15 and 12 for $\mathbf{1}$ and $\mathbf{3}$, respectively (Table 4). Bulk electrolysis using a mercury pool electrode resulted in less efficiency for all complexes, with a hydrogen sulfide smell evolving after the end of the experiment that indicates a degree of catalyst degradation.

In order to find out if a catalytic process occurs at the potential corresponding to the formation of the dianion - as the enhancement of the peak current implies - bulk electrolysis experiments have also been performed at $-1.3 \mathrm{~V} \mathrm{vs} \mathrm{Fc}{ }^{+/ 0}$ for complexes 1 and 2 . Catalyst 1 and 2 achieved 5 and 1 TONs corresponding to $\mathrm{H}_{2}$ evolution with $57 \%$ and $34 \%$ faradaic yield, respectively indicating that this catalytic process is rather reduced but not missing, in accordance with DFT calculations.

Taking into consideration that the hydrogen evolving systems reported up to now with dithiolene catalysts perform better when the catalyst is in lower concentration $(\mu \mathrm{M}$ for photocatalysis and $10^{-4} \mathrm{M}$ in electrocatalysis [30,31,67]), we also employed catalyst 2 with a concentration of $0.1 \mathrm{mM}$. TON (determined from GC measurements) increased to 47 for the same time of bulk electrolysis (glassy carbon electrode, $3 \mathrm{~h}$ ), with the faradaic yield dropping to $23 \%$. Thus, we propose that higher catalyst concentrations could lead to destructive pathways between two dithiolene catalyst molecules. Cyclic voltammetry measurements performed on the bulk electrolysis solution at the end of the experiment display similar features as those of Figure S1. Furthermore, addition of iodine in the bulk electrolysis solution after the end of the experiment resulted in a color change from red to green, indicating oxidation of the red anionic species to the green neutral.

\section{Study of the decomposition of catalysts}

In order to investigate if decomposition of the catalyst occurs on the surface of the electrode - an implication of heterogeneous catalysis- rinse test experiments were performed in which, after three distinct experiments detailed below, the working electrode was rinsed with solvent and immersed again in a fresh solution of acid in order to examine if a catalytic activity remains in the absence of catalyst in solution. First, the glassy carbon working electrode has been conditioned through the measurement of a single cyclic voltammogram in acidic solutions of catalyst 2 . Little current enhancement was observed in CV measurement for the rinsed electrode (Figure 6). Second, a linear sweep voltammogram from -0.5 to -1.7 $\mathrm{V}$ vs $\mathrm{Fc}^{+/ 0}$ was measured in the presence of catalyst (Figure S5). This procedure should avoid that the deposit could be reoxidized (therefore cleaning the electrode surface) during the backward scan. However subsequent CV measurement starting from $-1.0 \mathrm{~V} \mathrm{vs} \mathrm{Fc}^{+/ 0}$ showed no current enhancement (Figure 7, red trace) in the potential region where catalysis occurs in the presence of catalyst (Figure 7, dotted gray trace). Third, we used a conditioning procedure previously reported to demonstrate deposition of NiS onto a glassy 
carbon electrode for a similar $\left[\mathrm{Ni}(\mathrm{bdt})_{2}\right]^{-}$complex [61]. The working electrode was poised for $3 \mathrm{~min}$ at a constant potential negative to the potential of the -1/-2 process and corresponding to the onset of the catalytic wave $\left(-1.65 \mathrm{~V} \mathrm{vs} \mathrm{Fc}^{+/ 0}\right)$. The subsequent recording of the cyclic voltammogram (Figure 7, black trace) indicated that there was little enhancement of the catalytic wave in the absence of catalyst. The same behavior was observed with catalyst 1 (see Figure S6, supporting information). Finally, the linear dependence of $i_{\text {cat. }}$ on the square root of scan rate (Figure 8) indicated a homogeneous, diffusion-controlled process [65]. All the above experiments indicate that under the experimental conditions reported in this work, homogeneous catalysis occurs at the surface of the electrode.

\section{Computational investigation of the hydrogen evolution mechanism}

DFT calculations were employed to investigate the possible reaction pathways for the hydrogen evolution by catalysts $\mathbf{1}-\mathbf{3}$ and their monoanions. The electronic structure of all the stationary points along the reaction path were characterized and the redox potentials of the electron transfer steps as well as the energies of the proton transfer processes were calculated. Although these computed energies can be different from the experimental values, often by as much as $300 \mathrm{mV}$ [68], the calculations nevertheless provide invaluable insights into what is observed experimentally.

The geometries of the neutral complexes and their monoanions were fully optimized in DMF from their experimental X-ray single crystal structures as determined herein and the literature [51]. The calculated geometries in solvent are in good agreement with the experimental ones, with the calculated bond lengths and angles within $0.01 \AA$ and $2^{0}$, respectively. There is an exception for the $\mathrm{Ni}-\mathrm{S}$ bond lengths, which are overestimated by as much as $0.04 \AA$, but this is anticipated with DFT calculations. Calculated structural parameters, namely bond lengths and S-Ni-S dihedral angles for complex 1, its monoanion and all of its intermediates are summarized in Table 5.

The proposed mechanism for the $2 \mathrm{e}^{-} / 2 \mathrm{H}^{+}$reduction/protonation of $\mathbf{1}$ leading to the evolution of hydrogen is shown in Scheme 4. All the protonation energies were computed with respect to the $\mathrm{CF}_{3} \mathrm{COOH} / \mathrm{CF}_{3} \mathrm{COO}^{-}$couple and the standard redox potential, $E^{o}$, was calculated using the relation $\mathrm{E}^{\mathrm{o}}=\left(-\Delta \mathrm{G}^{0} / \mathrm{nF}\right)-\mathrm{E}_{\text {ref }}^{\mathrm{O}}$, where $\Delta G^{0}$ is the free energy of reduction, $n$ is the number of electrons being transferred, $F$ is the Faraday constant and $E_{r e f}^{o}$ is the absolute reduction potential of the ferrocene couple computed at the same level of theory. As Scheme 4 indicates the mechanism initially involves reduction to the monoanion followed by the reduction to the dianion and the next step is the protonation of the latter which proceeds downhill by $61 \mathrm{~kJ} . \mathrm{mol}^{-1}$. Overall, this scheme agrees with our experimental findings in which hydrogen is produced after formation of dianion and it is also identified as the favorable path when compared with protonation of the monoanion, yielding $[\mathbf{1}(\mathrm{S}-\mathrm{H})]$ which is computed to be endothermic by as much as $18 \mathrm{~kJ} \cdot \mathrm{mol}^{-1}$. Moreover, protonation of the monoanion at nickel atom is less favorable to $[\mathbf{1}(\mathrm{S}-\mathrm{H})]$ by $74 \mathrm{~kJ} \cdot \mathrm{mol}^{-1}$. These calculations indicate that the most favorable protonation site of the dianion of $\mathbf{1}$ is on any one of the sulfur atoms of the dithiolene ligands rather than the nickel atom. Indeed, the nickel - protonated counterpart $[\mathbf{1}(\mathrm{NiH})]^{-}$is less stable by $64 \mathrm{~kJ} \cdot \mathrm{mol}^{-1}$ than $[\mathbf{1}(\mathrm{SH})]^{-}$(Scheme 4). After the first protonation, 
two different steps can take place; either a second protonation via a thermoneutral reaction $\left(-14 \mathrm{~kJ} \mathrm{~mol}^{-1}\right)$ (route A) or reduction and then protonation (route B).

Protonation of $[\mathbf{1}(\mathrm{SH})]^{-}$(route A) leads only to one intermediate, which is doubly protonated on two sulfur atoms on distinct dithiolene rings, namely [1(SH-SH)]. Hydrogen evolution from this state to afford complex $\mathbf{1}$ is slightly exergonic by $-25 \mathrm{~kJ} \mathrm{~mol}^{-1}$ (route $\mathrm{A}_{1}$, Scheme 4) in accordance with the experimental evidence of catalytic $\mathrm{H}_{2}$ evolution at the potential of the $-1 /-2$ process. [ $1(\mathrm{SH}-\mathrm{SH})]$ is calculated to be more stable than the state where both protons are on sulfur atoms of the same chelate ring by $32 \mathrm{~kJ} \mathrm{~mol}^{-1}$. Subsequent reduction with a potential of $-1.3 \mathrm{~V}$ vs Fc$c^{+/ 0}$ (compared to experimental $-1.75 \mathrm{~V} \mathrm{vs} \mathrm{Fc}^{+/ 0}$ ) leads to the reduced diprotonated intermediate $[\mathbf{1}(\mathrm{SH}-\mathrm{SH})]^{-}$(route $\mathrm{A}_{2}$, Scheme 4$)$. This intermediate can also be reached via the alternative route $\mathrm{B}$, since the singly protonated $[\mathbf{1}(\mathrm{SH})]^{-}$is reduced at $-1.9 \mathrm{~V}_{\mathrm{vs} \mathrm{Fc}}{ }^{+/ 0}$ (compared to the $-1.9 \mathrm{~V}$ vs $\mathrm{Fc}^{+/ 0}$ experimentally observed) to produce $[\mathbf{1}(\mathrm{SH})]^{2-}$. For this reduction process one has a unique singly protonated singly reduced species but two singly protonated doubly reduced species that are close in energy. The singly reduced species has the proton on a $S$ atom whereas the two doubly reduced species have protons on either a $\mathrm{S}$ atom or the metal. In each case, however, reduction occurs primarily on the sulfur atoms (> 1 electron gain in charge) with small compensating changes on the other atoms. For the doubly reduced species with S-protonation, the protonated $\mathrm{S}$ atom gains a similar amount of negative charge as the other three $\mathrm{S}$ atoms.By comparaison to the $\mathrm{S}$ protonated doubly reduced species, the proton atom gains - -0.30 units of charge in the metal-protonated doubly reduced species, indicative of its hydride nature.

Our calculations indicate that $[\mathbf{1}(\mathrm{SH})]^{2-}$ is more stable than the $[\mathbf{1}(\mathrm{NiH})]^{2-}$ by only 1 $\mathrm{kJ} . \mathrm{mol}^{-1}$, thereby not excluding the possibility of nickel ion protonation. However, the next step - protonation of the dianion - yields the species $[\mathbf{1}(\mathrm{SH}-\mathrm{SH})]^{-}$, in an energetically

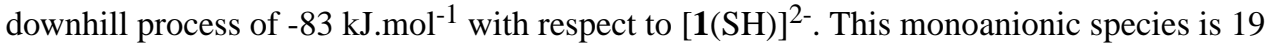
$\mathrm{kJ} . \mathrm{mol}^{-1}$ more stable than the one with two protons on the same sulfur ligand, and no stable species protonated at nickel was observed. Other studies have suggested that a Ni-hydride intermediate is formed before hydrogen evolution [32] but this is probably due to the differences in the electronic properties of the dithiolene ligands that we employ. From this point, the evolution of hydrogen proceeds via an exothermic reaction by $-140 \mathrm{~kJ} \cdot \mathrm{mol}^{-1}$ yielding the monoanion of complex $\mathbf{1}$, which therefore acts as the catalyst for the reduction of $\mathrm{H}^{+}$. According to our experimental data (Figure 5) the two routes compete at low ratios of acid to catalyst (1-3eq of acid) whereas at higher ratios ( $\geq 10 \mathrm{eq}$ ) route A saturates and route $\mathrm{B}$ appears dominant. The calculated structures for the intermediates along with the catalytic cycle are shown in Figure 9. Holding the potential value at $-1.67 \mathrm{~V}$ vs $\mathrm{Fc}^{+/ 0}$ in the bulk electrolysis experiment makes route A prevail, since route B requires significantly more negative potential values.

In route $\mathrm{B}$ the formation of the protonated $[\mathbf{1}(\mathrm{NiH})]^{2-}$ species is possible but no stable species protonated at both sulfur and nickel could be found as mentioned before. These findings are in contrast to the ones for the related cobalt dithiolene complexes. In fact, extensive studies on cobalt dithiolenes by Letko et al. [33] revealed that a $\mathrm{Co}-\mathrm{H}$ intermediate species is formed in the hydrogen evolution cycle. More specifically, the monoanionic cobalt species is reduced to the dianion and protonation occurs at the cobalt 
ion. Subsequent reduction and protonation leads to a $(\mathrm{Co}-\mathrm{H}) /(\mathrm{S}-\mathrm{H})$ diprotonated species that releases dihydrogen. However, we propose that in nickel aryl-dithiolene complexes the protonation and redox effects are located mainly on the ligand framework, due to the decreased contribution of $\mathrm{Ni}$ orbitals $-\sim 25 \% 3 \mathrm{~d} \mathrm{Ni}$ orbitals for all three oxidation states of the similar [ $\mathrm{Ni}\left(\mathrm{S}_{2} \mathrm{C}_{2} \mathrm{Me}_{2}\right)_{2}$ ] complexes [69], opposed to $62 \%$ for Co complexes [33]. As observed earlier [57] for the similar compound $\left[\mathrm{Ni}\left(\mathrm{S}_{2} \mathrm{C}_{2} \mathrm{Me}_{2}\right)_{2}\right]$ across the 0/-1/-2 oxidation states, the redox events take place on the ligands due to the increased contribution of $S\left(3 p_{z}\right)$ in the $5 b_{2 g} \mathrm{MO}$, even though the $\mathrm{Ni}$ contribution increases upon reduction to the dianion. We propose this is also the case for the nickel dithiolene complexes under study.

Upon protonation after the reduction to the dianionic state $[1]^{2-}$, only a minor tetrahedral distortion is observed $\left(2.32^{\circ}\right)$ for intermediate $[\mathbf{1}(\mathrm{S}-\mathrm{H})]^{-}$. Subsequent protonation as discussed before (route A) leads to a more distorted structure $\left(8.87^{\circ}\right.$ for $\left.[\mathbf{1}(\mathrm{SH}-\mathrm{SH})]\right)$. In route $\mathrm{B}$ the generated $[\mathbf{1}(\mathrm{SH})]^{2-}$ exhibits a dihedral $\mathrm{S}-\mathrm{Ni}-\mathrm{S}$ angle of $20.44^{\circ}$, whereas the corresponding $[\mathbf{1}(\mathrm{NiH})]^{2-}$ intermediate (see Figure $\mathrm{S} 6$ ) exhibits a calculated $\mathrm{S}-\mathrm{Ni}-\mathrm{S}$ dihedral angle of $75.04^{\circ}$. When the diprotonated and reduced state [1(SH-SH)] - is reached, the dihedral angle is calculated to be $39.93^{\circ}$, which is much larger than in the neutral form. Another important parameter is the $\mathrm{H}$... H distance in the protonated intermediates, which increases from $3.0 \AA$ in $[1(\mathrm{SH}-\mathrm{SH})]$ to $4.0 \AA$ in [1(SH-SH) $]^{-}$. Additional studies, including explicit dynamics of the complexes, are therefore required to identify the mechanism for $\mathrm{H}_{2}$ evolution from these species. Alternatively, transient cleavage of a Ni-S bond, as observed in some higher energy species in the course of our DFT studies (data not shown), with hydrogen passage via the nickel might be envisaged.

For the symmetric tetramethoxy complex $\mathbf{3}$, the mechanism proposed is the same as for $\mathbf{1}$ with the analogous intermediates.

In the case of the asymmetric dithiolene complex $\mathbf{2}$, the same general mechanism is proposed (Scheme S1, supporting information). Metal dithiolene complexes with asymmetric dithiolene ligands show fluxional behavior in solution [70]. This prompted us to calculate the intermediates of both the cis- and trans- isomers. Similar $\Delta \mathrm{G}$ values for the reactions involving the protonated intermediates were found for the isomers but there is a difference in the reduction potential values, with the trans- isomer and its protonated forms exhibiting more negative reduction potentials. Overall, these calculated values compare well with our experimental data. In the final step where hydrogen is evolved by this catalyst, the trans-protonated complex releases hydrogen in a more exergonic process $\left(-154 \mathrm{~kJ}^{\mathrm{mol}}{ }^{-1}\right)$ in comparison to the cis- form of the complex $\left(-123 \mathrm{~kJ}_{\mathrm{mol}}{ }^{-1}\right)$.

This difference suggests that the electron donating ability of the trans methoxy groups preferentially enriches the sulfur atom which participates in the protonation, and this is proposed to be the sulfur atom proximal to the 4-methoxyphenylphenyl group of $\mathbf{2}$ (Figure S2). However based on the calculated values both isomers can be expected to be active catalysts with the observed activity being a suitable average of the process for both.

Moreover, theoretical data indicates that the asymmetric substitution of the phenyl groups reflect on the charges of the sulfur atoms, with the atoms S1 and S3 (Figure 2) to be always more negative compare to S2 and S4 (actually the slight differences are 0.02, 0.01 and 0.03e 
for the neutral, monoanion and dianion, respectively). This discrepancy between reduction potential and free energy values for the trans- and cis- isomers along with the different structural features that the asymmetric complex exhibits, can account for the fact that $\mathbf{2}$ is a better catalyst than $\mathbf{1}$ and $\mathbf{3}$, with the series being eventually $\mathbf{2}>\mathbf{3}>\mathbf{1}$.

\section{Conclusions}

Experimental and theoretical investigation of a series of methoxy-substituted aryldithiolene nickel complexes provides insight into the hydrogen evolving mechanism for these complexes. In each case, the sulfur atoms of the doubly reduced catalyst are more nucleophilic than when the catalyst is in other oxidation states, since upon reduction charge is stored on the ligands with the Ni retaining a +2 charge throughout the series neutral/ monoanion/dianion. The mechanisms proposed include reduction of the catalyst to the dianion, protonation at sulfur and subsequent protonation and reduction (route $\mathrm{A}$ ) or reduction and then protonation (route B), both leading to abstraction of hydrogen in an exergonic process that regenerates the monoanionic catalyst.

We propose that the presence of methoxy groups in the asymmetric catalyst $\mathbf{2}$ renders the sulfur atom S2 more nucleophilic than S1 due to partial localization of charge on S2 (thiolate form). Thus, the higher activity of $\mathbf{2}$ is explained on the grounds of the asymmetric nature of the ligand.

The observation that the complex after protonation and further reduction adopts a highly distorted tetrahedral structure, witnessed by the calculated dihedral angle changes between S1-Ni1-S2 and S3-Ni1-S4, indicates that the catalysts must undergo a significant geometrical distortion in order for hydrogen to evolve. It is possible that this large change could be responsible for impeding the hydrogen evolving activity of these compounds. This may be reflected on the reduced activity of the compounds in the hydrogen evolving reaction. The high overpotential values required for compounds $\mathbf{1}-\mathbf{3}$ to sustain catalysis are a limiting factor for the applicability of these systems in hydrogen evolving cathodes, but indepth analysis of the mechanistic aspects involved in the reaction steps can lead to the design and study of more effective catalysts with more rigid structures and reduced charge delocalization over the $\mathrm{NiS}_{4}$ core. The determination of structure-activity relationships within this class of compounds is therefore underway in our group with the aim of developing improved-by-design catalysts.

\section{Supplementary Material}

Refer to Web version on PubMed Central for supplementary material.

\section{Acknowledgments}

Funding from the Special Research Account of NKUA and COST action CM1202 PERSPECT H2O is greatly appreciated. AZ greatly appreciates funding from COST action CM1202 for a STSM. This work was supported by the French National Research Agency (Labex program, ARCANE, ANR-11-LABX-0003-01 and NiFe-Cat project, ANR-10-BLAN-7-11), the European Research Council under the European Union's Seventh Framework Programme (FP/2007-2013)/ERC Grant Agreement n.306398 and the Life Science Division of CEA (2011 DSVEnergy program). 


\section{References}

[1]. Cook TR, Dogutan DK, Reece SY, Surendranath Y, Teets TS, Nocera DG. Chem Rev. 2010; 110:6474. [PubMed: 21062098]

[2]. Esswein AJ, Nocera DG. Chem Rev. 2007; 107:4022. [PubMed: 17927155]

[3]. Artero V, Chavarot-Kerlidou M, Fontecave M. Angew Chem Int Ed. 2011; 50:7238.

[4]. Kawano K, Yamauchi K, Sakai K. Chem Commun. 2014; 50:9872.

[5]. Eckenhoff WT, McNamara WR, Du P, Eisenberg R. Biochim Biophys Acta BBA - Bioenerg. 2013; 1827:958.

[6]. Dempsey JL, Brunschwig BS, Winkler JR, Gray HB. Acc Chem Res. 2009; 42:1995. [PubMed: 19928840]

[7]. Queyriaux N, Jane RT, Massin J, Artero V, Chavarot-Kerlidou M. Coord Chem Rev. 2015; 304305:3.

[8]. Kaeffer N, Chavarot-Kerlidou M, Artero V. Acc Chem Res. 2015; 48:1286. [PubMed: 25941953]

[9]. Zee DZ, Chantarojsiri T, Long JR, Chang CJ. Acc Chem Res. 2015; 48:2027. [PubMed: 26101803]

[10]. Ginovska-Pangovska B, Dutta A, Reback ML, Linehan JC, Shaw WJ. Acc Chem Res. 2014; 47:2621. [PubMed: 24945095]

[11]. Begum A, Moula G, Sarkar S. Chem - Eur J. 2010; 16:12324. [PubMed: 20853299]

[12]. Simmons TR, Berggren G, Bacchi M, Fontecave M, Artero V. Coord Chem Rev. 2014; 270 271:127.

[13]. Lubitz W, Ogata H, Rüdiger O, Reijerse E. Chem Rev. 2014; 114:4081. [PubMed: 24655035]

[14]. Gomez-Mingot M, Porcher J-P, Todorova TK, Fogeron T, Mellot-Draznieks C, Li Y, Fontecave M. J Phys Chem B. 2015

[15]. Henning R, Schlamann W, Kisch H. Angew Chem Int Ed Engl. 1980; 19:645.

[16]. Katakis DF, Mitsopoulou C, Konstantatos J, Vrachnou E, Falaras P. J Photochem Photobiol Chem. 1992; 68:375.

[17]. Zarkadoulas A, Koutsouri E, Mitsopoulou CA. Coord Chem Rev. 2012; 256:2424.

[18]. Islam A, Sugihara H, Hara K, Singh LP, Katoh R, Yanagida M, Takahashi Y, Murata S, Arakawa H, Fujihashi G. Inorg Chem. 2001; 40:5371. [PubMed: 11578182]

[19]. Islam A, Sugihara H, Hara K, Singh LP, Katoh R, Yanagida M, Takahashi Y, Murata S, Arakawa H. J Photochem Photobiol Chem. 2001; 145:135.

[20]. Eisenberg R, Gray HB. Inorg Chem. 2011; 50:9741. [PubMed: 21913669]

[21]. Sproules S, Wieghardt K. Coord Chem Rev. 2011; 255:837.

[22]. Queen MS, Towey BD, Murray KA, Veldkamp BS, Byker HJ, Szilagyi RK. Coord Chem Rev. $2013 ; 257: 564$.

[23]. Mitsopoulou CA. Coord Chem Rev. 2010; 254:1448.

[24]. Sellmann D, Geck M, Moll M. J Am Chem Soc. 1991; 113:5259.

[25]. Vlček A Jr, Vlček AA. Inorganica Chim Acta. 1980; 41:123.

[26]. Humphry-Baker R, Mitsopoulou CA, Katakis D, Vrachnou E. J Photochem Photobiol Chem. 1998; $114: 137$.

[27]. Katakis D, Mitsopoulou C, Vrachnou E. J Photochem Photobiol Chem. 1994; 81:103.

[28]. Lyris E, Argyropoulos D, Mitsopoulou C-A, Katakis D, Vrachnou E. J Photochem Photobiol Chem. 1997; 108:51.

[29]. Mitsopoulou C, Lyris E, Veltsos S, Katakis D. Inorg React Mech. 2001; 3:99.

[30]. McNamara WR, Han Z, Alperin PJ, Brennessel WW, Holland PL, Eisenberg R. J Am Chem Soc. 2011; 133:15368. [PubMed: 21863808]

[31]. McNamara WR, Han Z, (Madeline) Yin C-J, Brennessel WW, Holland PL, Eisenberg R. Proc Natl Acad Sci. 2012; 109:15594. [PubMed: 22691494]

[32]. Solis BH, Hammes-Schiffer S. J Am Chem Soc. 2012; 134:15253. [PubMed: 22954257] 
[33]. Letko CS, Panetier JA, Head-Gordon M, Tilley TD. J Am Chem Soc. 2014; 136:9364. [PubMed: 24950387]

[34]. Das A, Han Z, Brennessel WW, Holland PL, Eisenberg R. ACS Catal. 2015; 5:1397.

[35]. Wang, K. Dithiolene Chem. John Wiley \& Sons, Inc; 2003. p. 267-314.

[36]. Sumrell G, Stevens JI, Goheen GE. J Org Chem. 1957; 22:39.

[37]. Cobo S, Heidkamp J, Jacques P-A, Fize J, Fourmond V, Guetaz L, Jousselme B, Ivanova V, Dau H, Palacin S, Fontecave M, et al. Nat Mater. 2012; 11:802. [PubMed: 22863815]

[38]. Oxford Diffraction. CrysAlis CCD and CrysAlis RED. Version 1.171.32.15. Oxford Diffraction Ltd; Abingdon, Oxford, England: 2008. n.d

[39]. Altomare A, Cascarano G, Giacovazzo C, Guagliardi A, Burla MC, Polidori G, Camalli M. J Appl Crystallogr. 1994; 27:435.

[40]. Sheldrick, GM. SHELXL-97, Program for Refinement of Crystal Structures. University of Göttingen; Germany: 1997.

[41]. Farrugia L. J Appl Crystallogr. 1999; 32:837.

[42]. Macrae CF, Bruno IJ, Chisholm JA, Edgington PR, McCabe P, Pidcock E, Rodriguez-Monge L, Taylor R, van de Streek J, Wood PA. J Appl Crystallogr. 2008; 41:466.

[43]. Neese F. Wiley Interdiscip Rev Comput Mol Sci. 2012; 2:73.

[44]. Sinnecker S, Rajendran A, Klamt A, Diedenhofen M, Neese F. J Phys Chem A. 2006; 110:2235. [PubMed: 16466261]

[45]. Konezny SJ, Doherty MD, Luca OR, Crabtree RH, Soloveichik GL, Batista VS. J Phys Chem C. 2012; 116:6349.

[46]. Bui T-T, Garreau-de Bonneval B, Moineau-Chane Ching KI. New J Chem. 2010; 34:337.

[47]. Papavassiliou GC, Anyfantis GC, Mousdis GA. Crystals. 2012; 2:762.

[48]. Chandrasekaran P, Arumugam K, Jayarathne U, Pérez LM, Mague JT, Donahue JP. Inorg Chem. 2009; 48:2103. [PubMed: 19235970]

[49]. Arumugam K, Bollinger JE, Fink M, Donahue JP. Inorg Chem. 2007; 46:3283. [PubMed: 17358055]

[50]. Kirk, ML., McNaughton, RL., Helton, ME. Dithiolene Chem. John Wiley \& Sons, Inc.; 2003. p. 111-212.

[51]. Miao Q, Gao J, Wang Z, Yu H, Luo Y, Ma T. Inorganica Chim Acta. 2011; 376:619.

[52]. Schrauzer GN, Mayweg VP. J Am Chem Soc. 1965; 87:3585.

[53]. Garreau-de Bonneval B, Moineau-Chane Ching KI, Alary F, Bui T-T, Valade L. Coord Chem Rev. 2010; 254:1457.

[54]. Schlaepfer CW, Nakamoto K. Inorg Chem. 1975; 14:1338.

[55]. Johnson, MK. Dithiolene Chem. John Wiley \& Sons, Inc.; 2003. p. 213-266.

[56]. Beswick, CL., Schulman, JM., Stiefel, EI. Dithiolene Chem. John Wiley \& Sons, Inc.; 2003. p. 55-110.

[57]. Lim BS, Fomitchev DV, Holm RH. Inorg Chem. 2001; 40:4257. [PubMed: 11487330]

[58]. Bowmaker GA, Boyd PDW, Campbell GK. Inorg Chem. 1983; 22:1208.

[59]. Fourmond V, Canaguier S, Golly B, Field MJ, Fontecave M, Artero V. Energy Environ Sci. 2011; $4: 2417$.

[60]. Felton GAN, Glass RS, Lichtenberger DL, Evans DH. Inorg Chem. 2006; 45:9181. [PubMed: 17083215]

[61]. Fang M, Engelhard MH, Zhu Z, Helm ML, Roberts JAS. ACS Catal. 2014; 4:90.

[62]. Fourmond V, Jacques P-A, Fontecave M, Artero V. Inorg Chem. 2010; 49:10338. [PubMed: 20964310]

[63]. Makedonas C, Mitsopoulou CA. Eur J Inorg Chem. 2006; 2006:590.

[64]. Costentin C, Passard G, Robert M, Saveant J-M. Chem Sci. 2013; 4:819.

[65]. Bard, JA., Faulkner, RL. Electrochemical Methods: Fundamentals and Applications. 2nd ed2001.

[66]. Savéant, J-M. Elements of Molecular and Biomolecular Electrochemistry: An Electrochemical Approach to Electron Transfer Chemistry. John Wiley \& Sons; 2006. 
[67]. Eckenhoff WT, Brennessel WW, Eisenberg R. Inorg Chem. 2014; 53:9860. [PubMed: 25163014]

[68]. Marenich AV, Ho J, Coote ML, Cramer CJ, Truhlar DG. Phys Chem Chem Phys. 2014; 16:15068. [PubMed: 24958074]

[69]. Szilagyi RK, Lim BS, Glaser T, Holm RH, Hedman B, Hodgson KO, Solomon EI. J Am Chem Soc. 2003; 125:9158. [PubMed: 15369373]

[70]. Argyropoulos D, Mitsopoulou C-A, Katakis D. Inorg Chem. 1996; 35:5549. [PubMed: 11666745] 


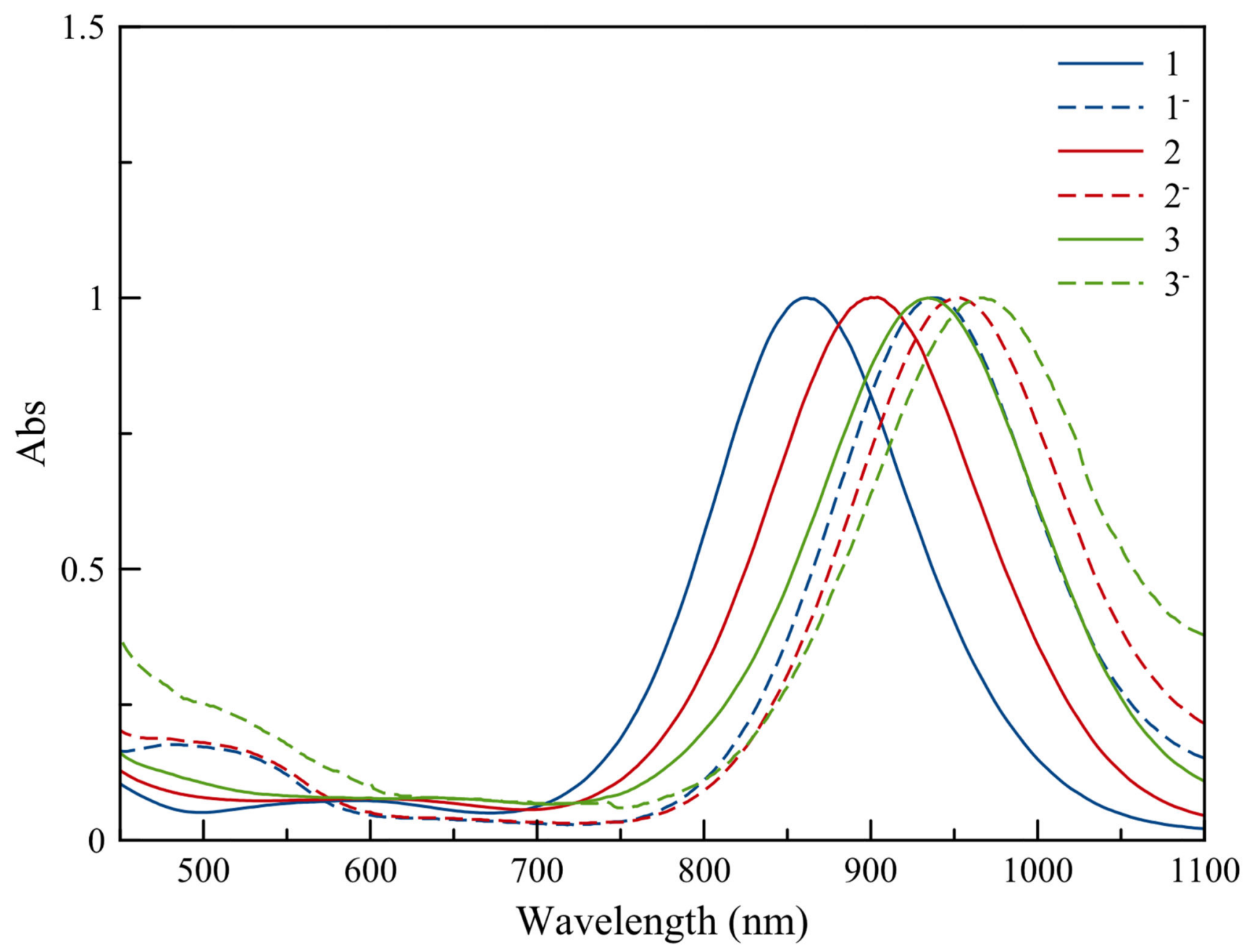

Figure 1.

Normalized absorption spectra for neutral complexes 1, 2, 3 and monoanionic complexes 1', 2-, 3-as tetrabutylammonium salts in DMF solution. 


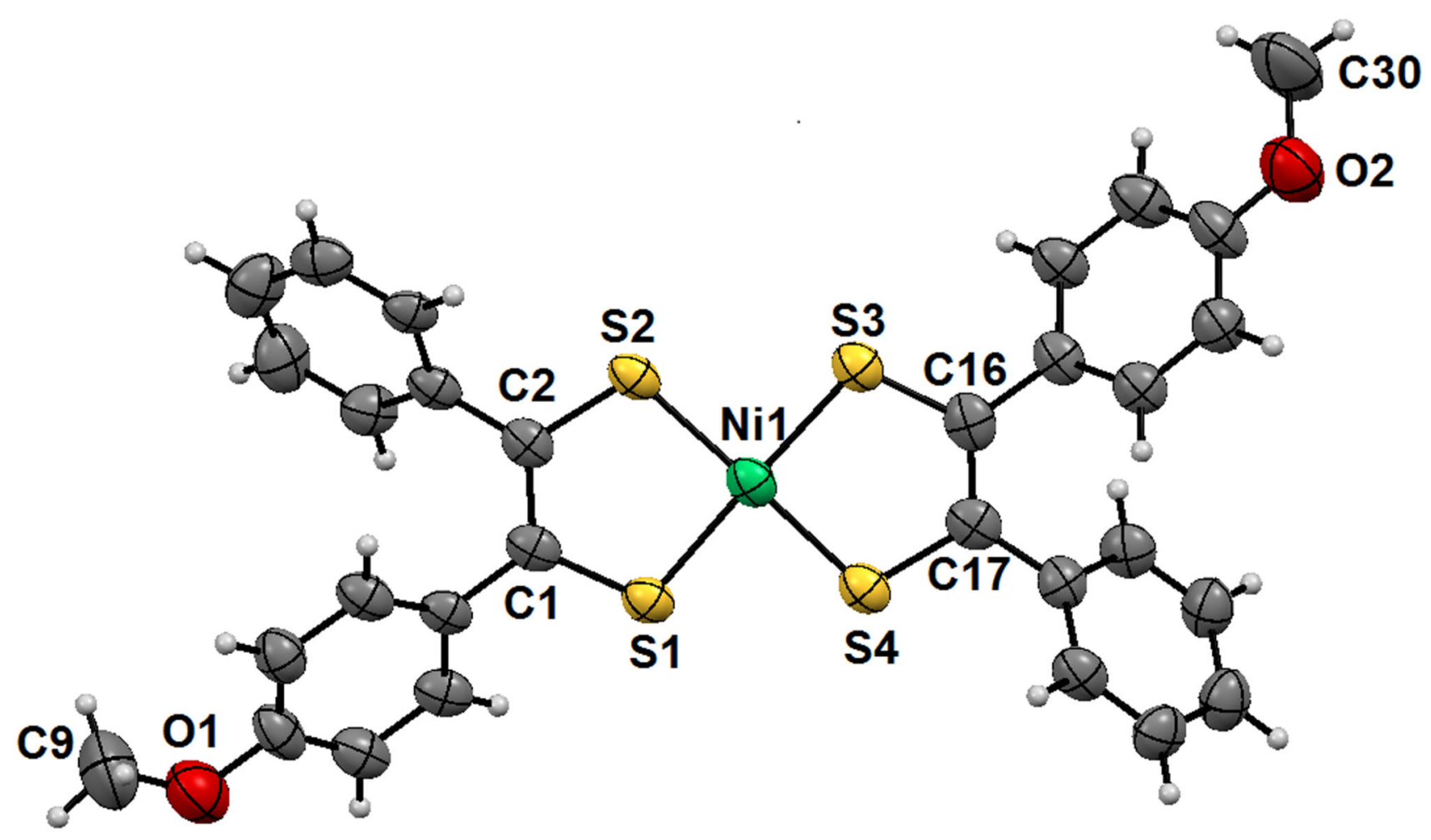

Figure 2.

ORTEP diagram at $30 \%$ probability level for compound 2. 


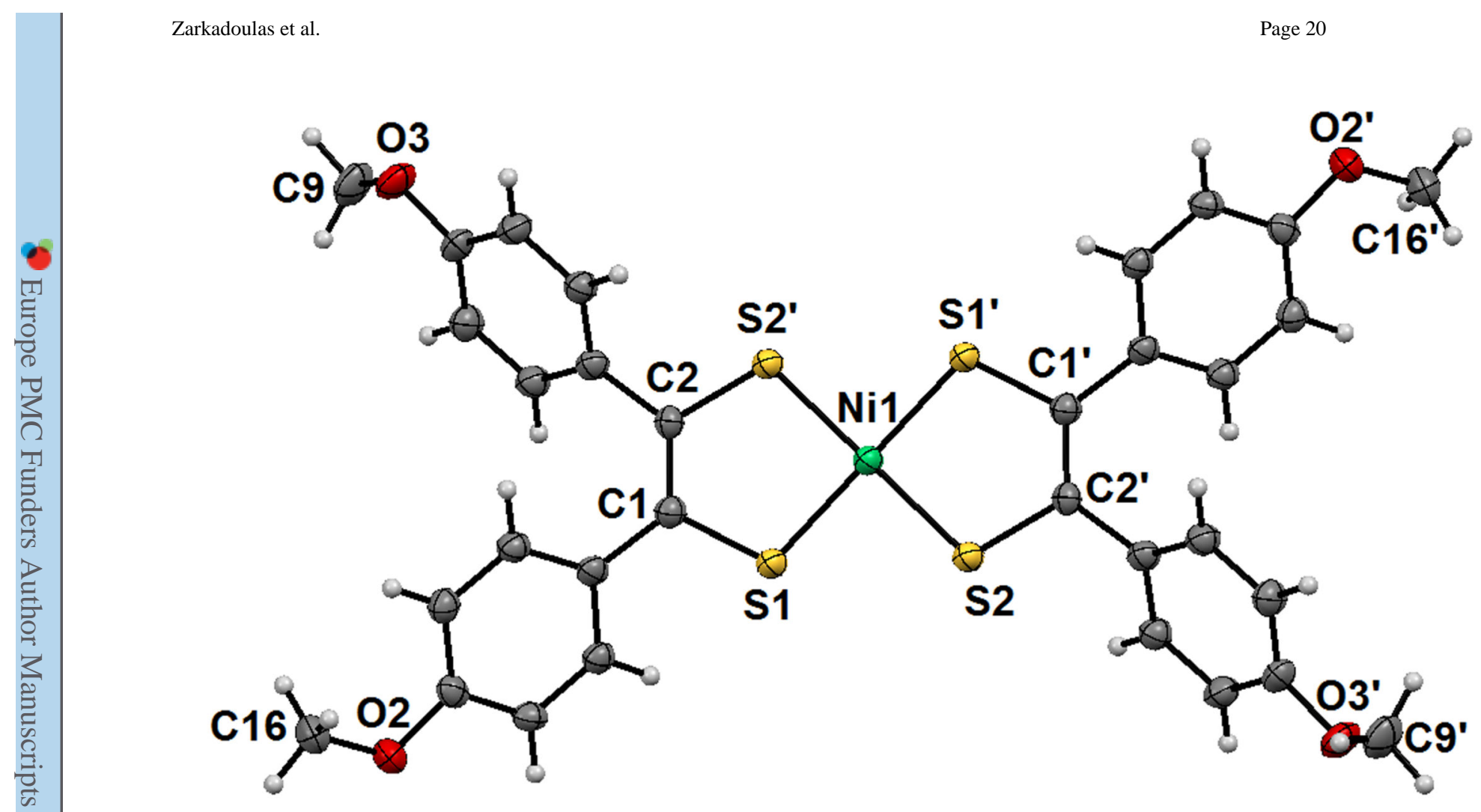

Figure 3.

ORTEP diagram at $30 \%$ probability level for compound $3^{-} . \mathrm{NBu}_{4}{ }^{+}$counter-ion is omitted for clarity. 


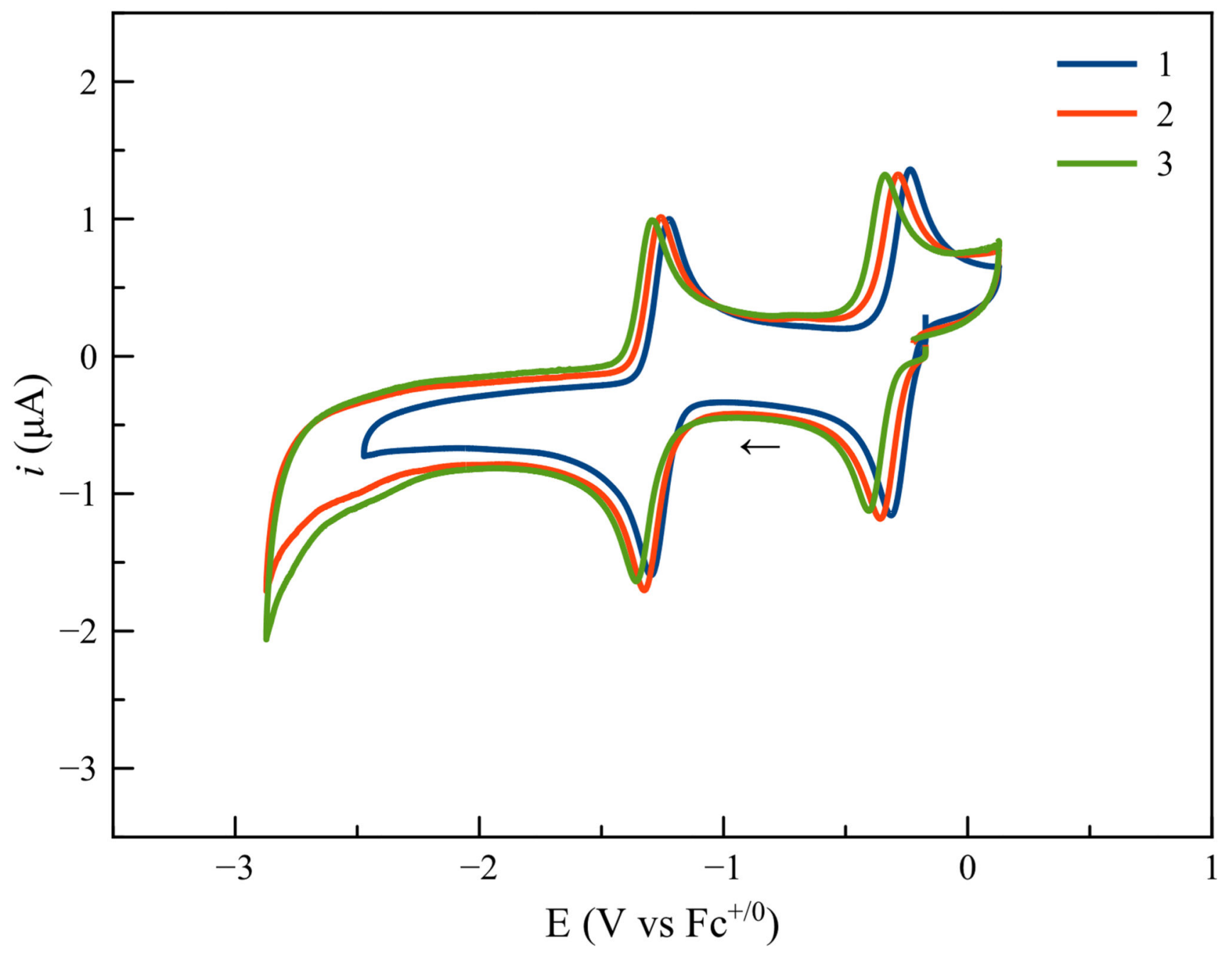

Figure 4.

Normalized cyclic voltammogramms for compounds $\mathbf{1}-\mathbf{3}$ in DMF at a scan rate of 100 $\mathrm{mV} \cdot \mathrm{s}^{-1}$ with $\mathrm{nBu}_{4} \mathrm{NPF}_{6}$ in DMF under Ar at room temperature (glassy carbon working electrode). 


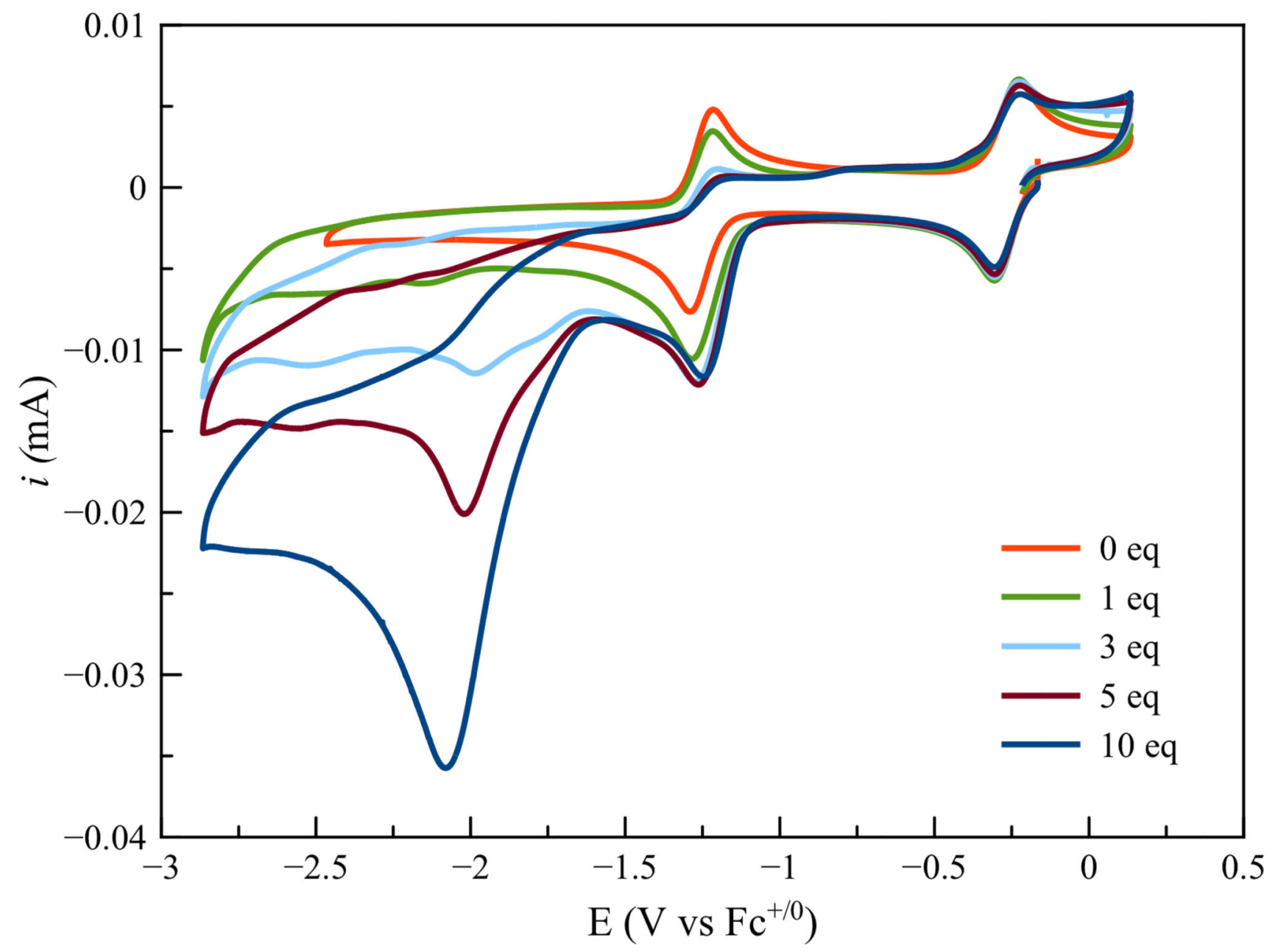

Figure 5.

Cyclic voltammogram of $\mathbf{1}$ in the presence of increasing equivalents of trifluoroacetic acid: no acid, red; 1 eq, green; 3 eq, light blue; 5 eq, burgundy; 10 eq, dark blue (glassy carbon working electrode). 


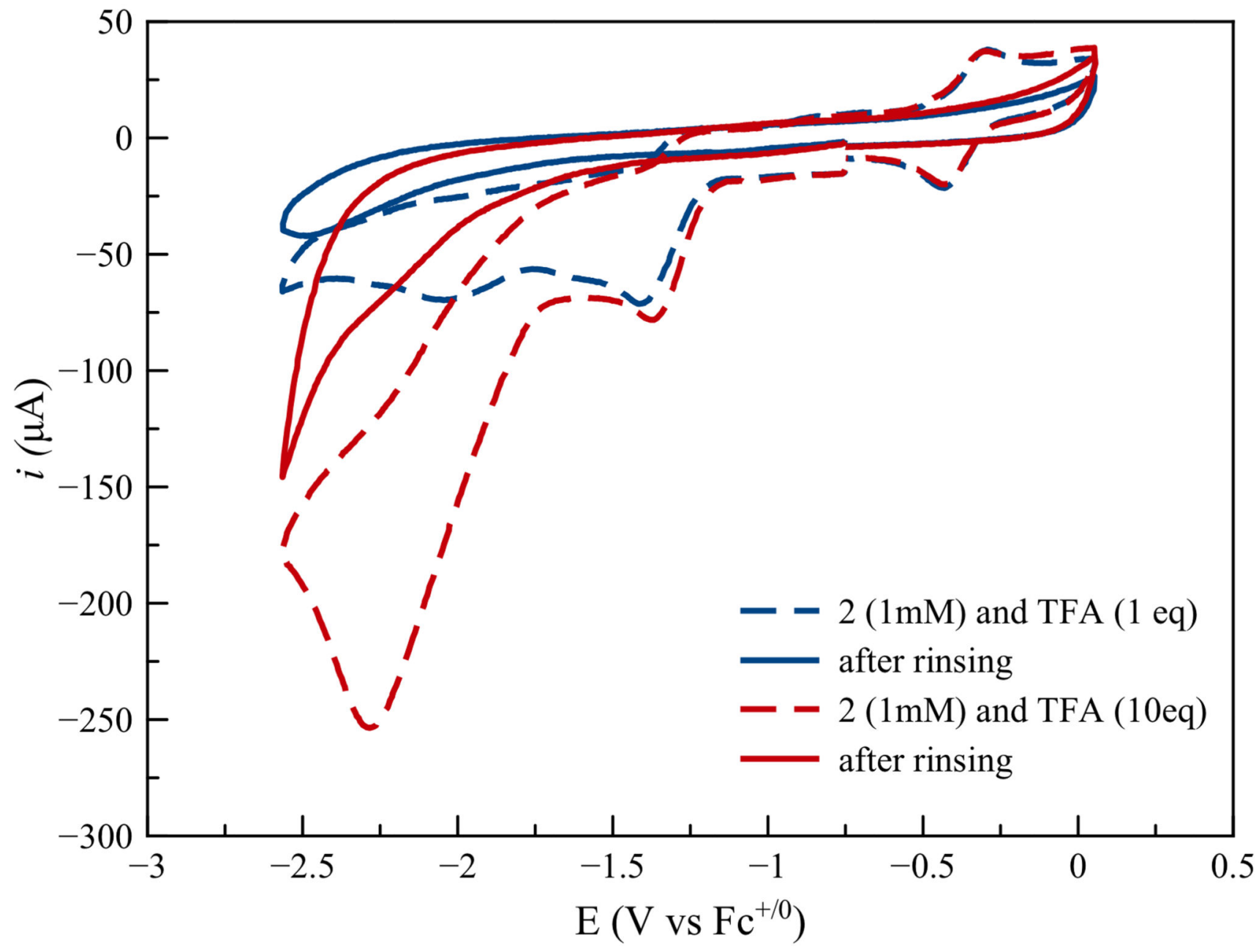

Figure 6.

Rinse tests for catalyst 2 in the presence of 1 eq and 10 eq TFA. Solid line: in the presence of catalyst, dashed line: absence of catalyst (glassy carbon working electrode). 


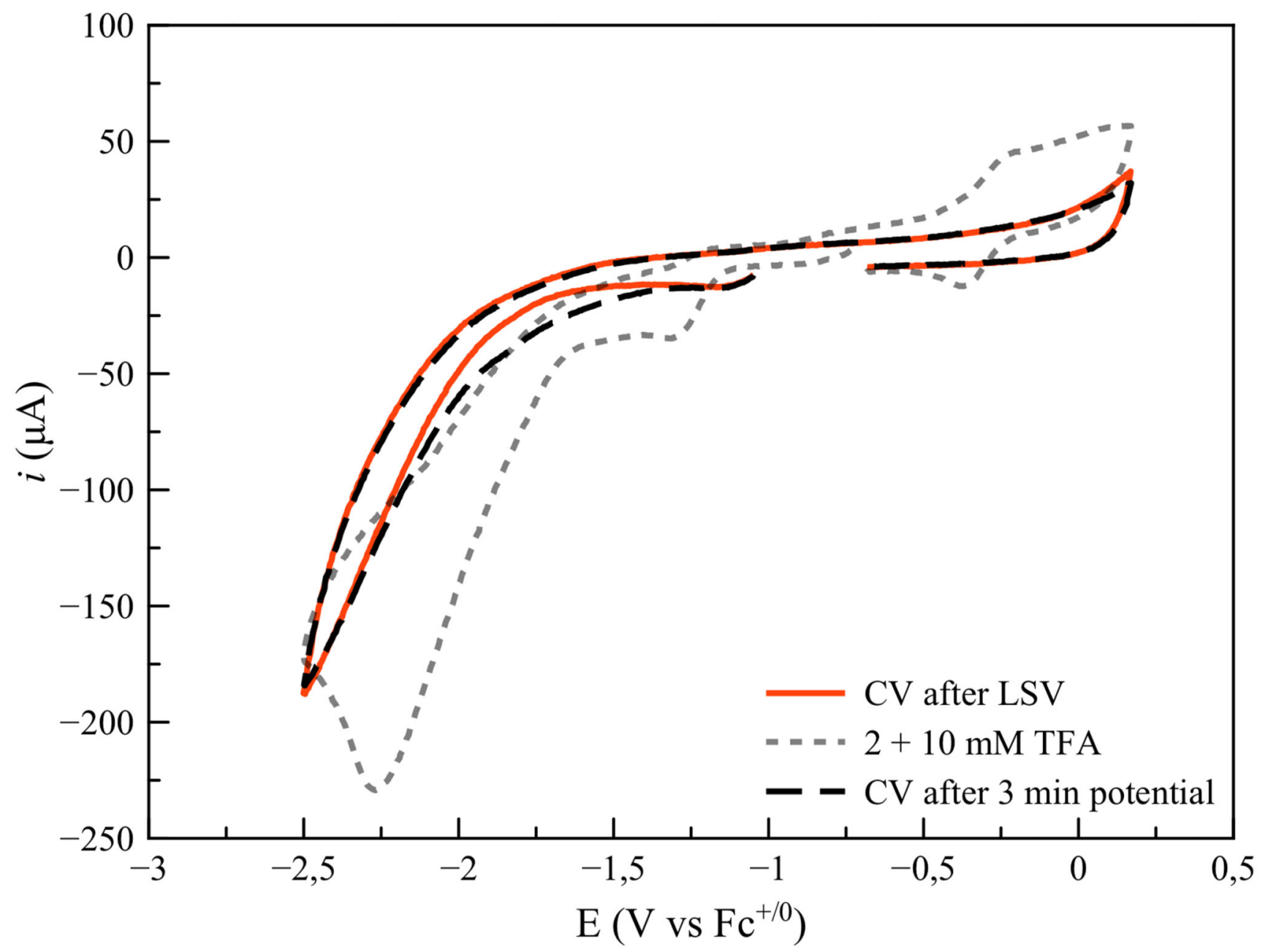

Figure 7.

Rinse tests for catalyst $\mathbf{2}$ in the presence of 10 eq TFA. grey trace: cyclic voltammogram in the presence of catalyst, red trace: cyclic voltammogram in the absence of catalyst starting from $-1.0 \mathrm{~V} \mathrm{vs} \mathrm{Fc}^{+/ 0}$ after linear sweep voltammetry, black trace: cyclic voltammogram in the absence of catalyst starting from $-1.0 \mathrm{~V} \mathrm{vs} \mathrm{Fc}^{+/ 0}$ after 3 min potential application (glassy carbon working electrode). 


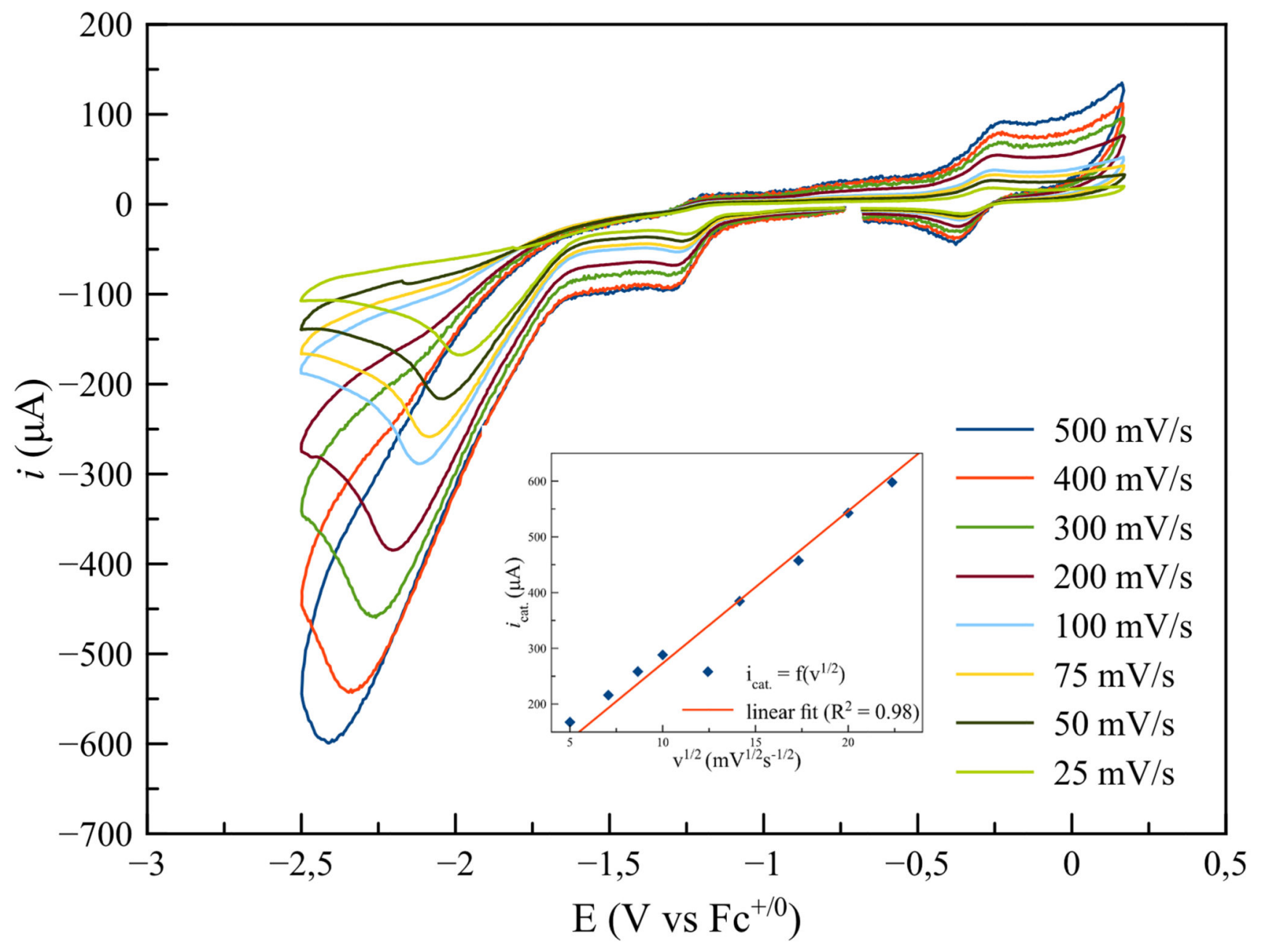

Figure 8.

Cyclic voltammogram of catalyst $\mathbf{2}$ in the presence of $10 \mathrm{mM}$ TFA at various scan rates. Inset: linear dependence of $i_{\text {cat. }} \mathrm{vs} \mathrm{v}^{1 / 2}\left(\mathrm{R}^{2}=0.97\right.$, glassy carbon working electrode) 


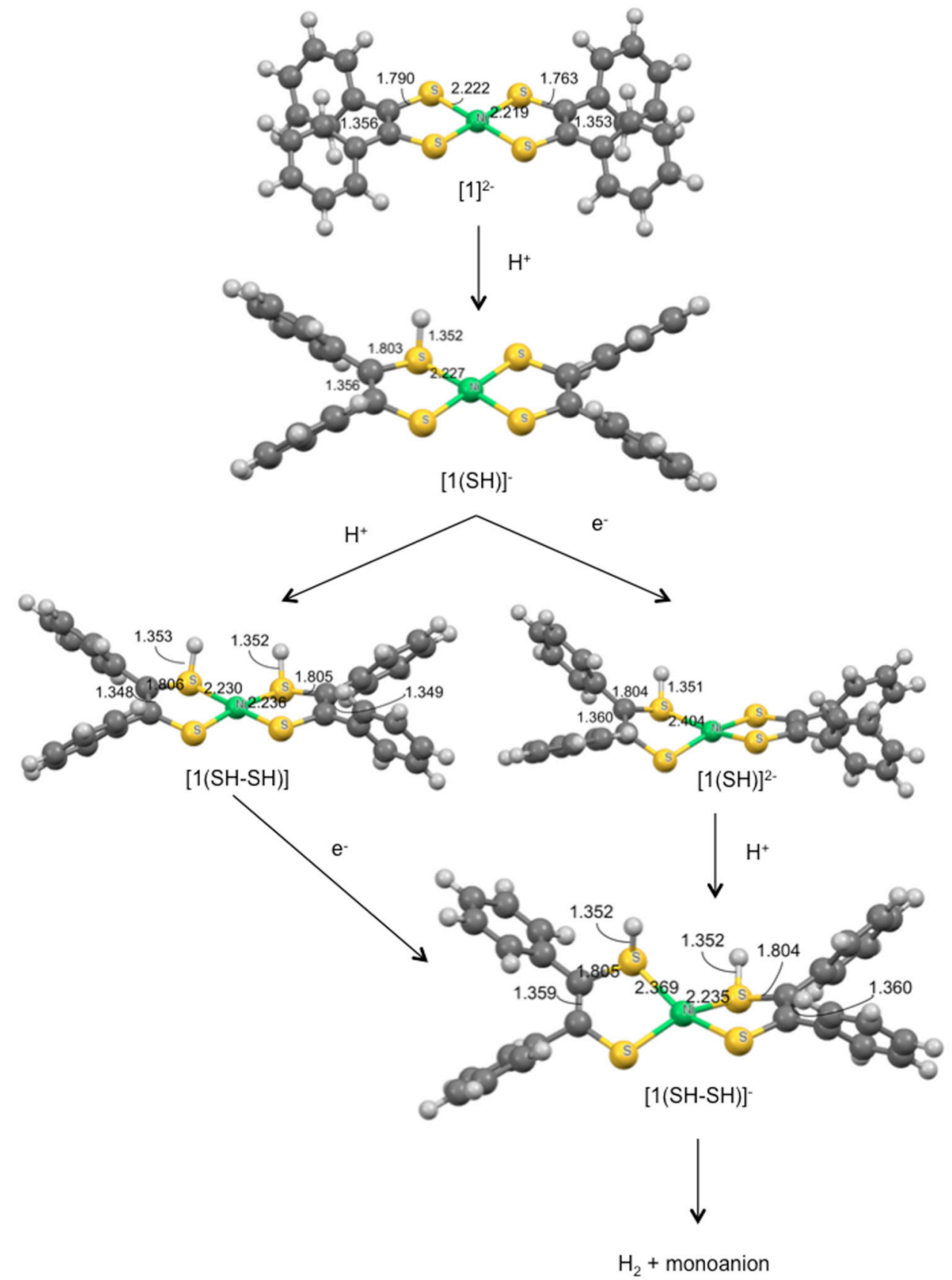

Figure 9.

Calculated structures for intermediates in the proposed hydrogen evolution mechanism for $\mathbf{1}$.

Inorg Chem. Author manuscript; available in PMC 2017 July 01. 


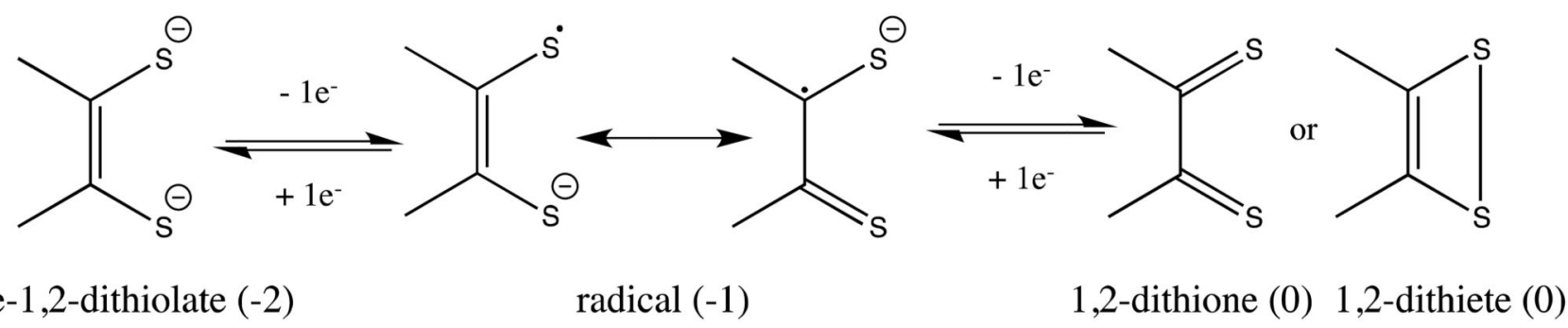

Scheme 1.

The oxidation states and nomenclature for a dithiolene ligand. 
<smiles>[R]c1ccc(C2=C(c3ccc([R])cc3)S[N+]3(S2)SC(c2ccc([R])cc2)=C(c2ccc([R])cc2)S3)cc1</smiles>

Scheme 2.

Structure of compounds under study.
1: $R=R^{\prime}=H$

2. $R=H, R^{\prime}=O M e$

3: $\mathrm{R}=\mathrm{R}^{\prime}=\mathrm{OMe}$

$1^{-}, 2^{-}, 3^{-}:$respective anionic complexes with $\mathrm{NBu}_{4}{ }^{+}$as counter-ion 


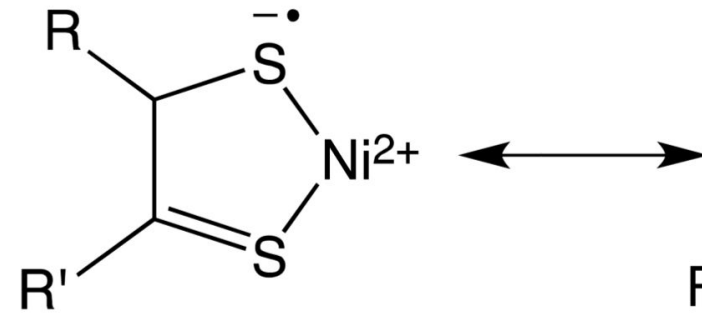

A

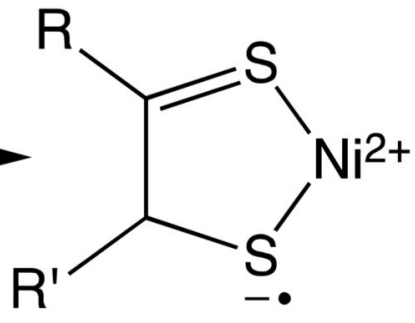

B

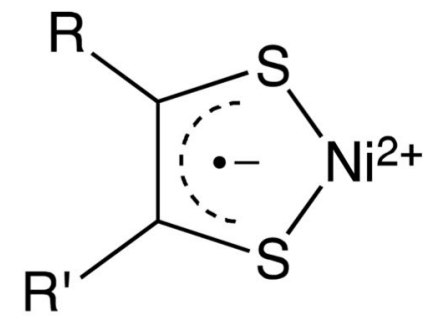

C

Scheme 3.

Limiting (A and B) and delocalized (C) structures for a Ni dithiolene complex. 

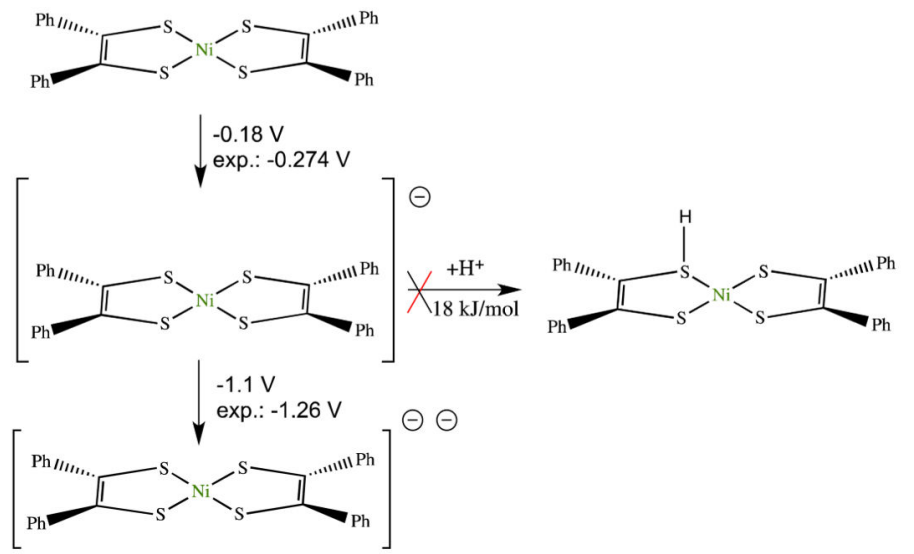

$\mathrm{H}^{+} \downarrow-61 \mathrm{~kJ} / \mathrm{mo}$
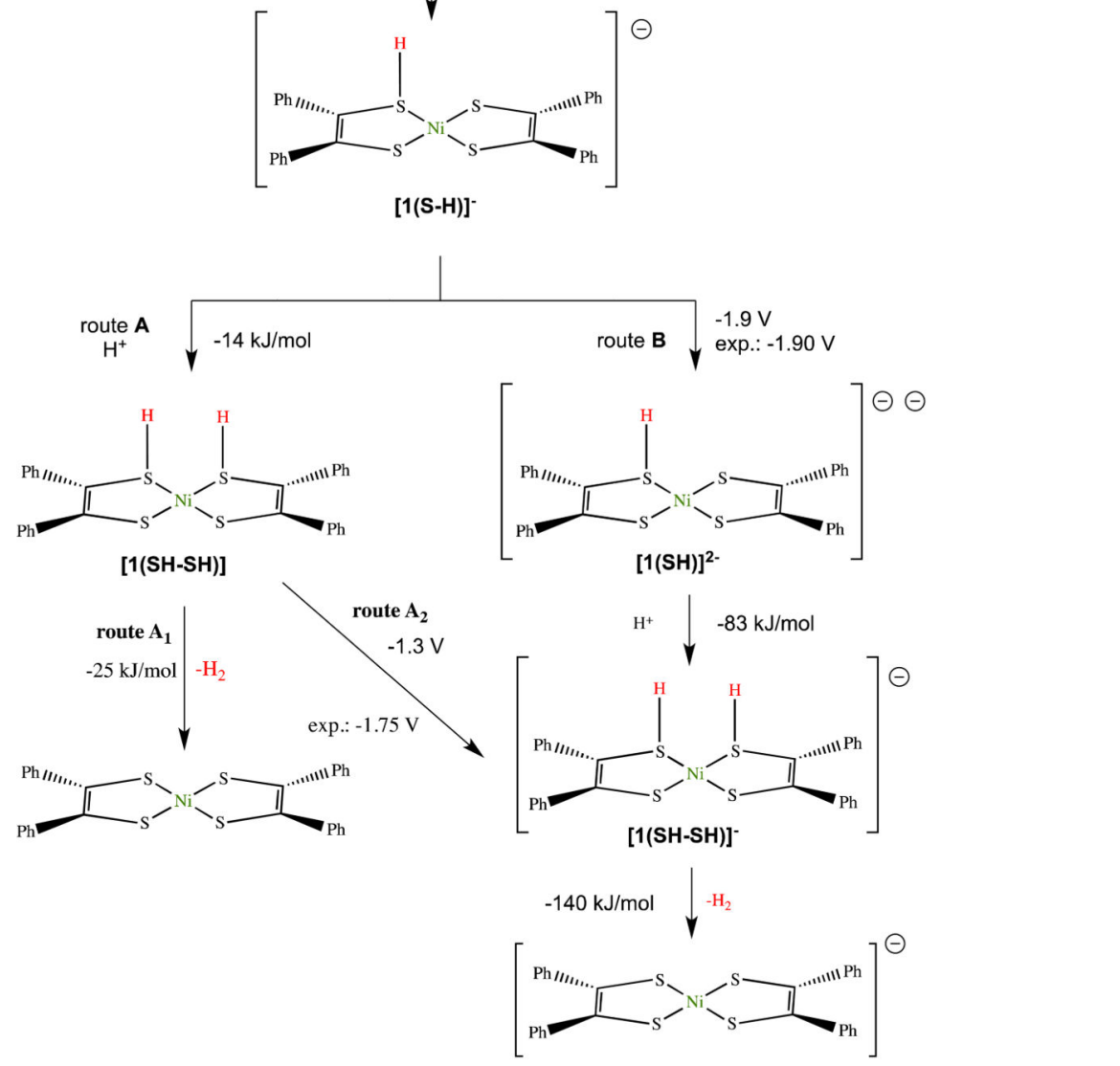

Scheme 4.

Proposed mechanism for hydrogen evolution with catalyst $\mathbf{1}$ together with calculated protonation enthalpies and redox potentials. Experimentally determined electrochemical potentials are also indicated. Potentials are reported vs $\mathrm{Fc}^{+/ 0}$. 


\section{Table 1}

Unit cell data and structure refinement details for compounds 2 and $\mathbf{3}^{-}$.

\begin{tabular}{|c|c|c|}
\hline Complex & 2 & 3- \\
\hline Empirical formula & $\mathrm{C}_{30} \mathrm{H}_{24} \mathrm{NiO}_{2} \mathrm{~S}_{4}$ & $\mathrm{C}_{48} \mathrm{H}_{64} \mathrm{NNiO}_{4} \mathrm{~S}_{4}$ \\
\hline Formula weight & 603.44 & 905.95 \\
\hline Crystal system & Triclinic & Triclinic \\
\hline Space group & $\mathrm{P} \overline{1}$ & $\mathrm{P} \overline{1}$ \\
\hline$a(\AA)$ & $9.975(5)$ & $9.6860(4)$ \\
\hline$b(\AA)$ & $10.495(5)$ & $15.9951(11)$ \\
\hline$c(\AA)$ & $13.500(5)$ & $16.9499(9)$ \\
\hline$a\left({ }^{\circ}\right)$ & $85.497(5)$ & $106.901(5)$ \\
\hline$\beta\left(^{\circ}\right)$ & $75.295(5)$ & $93.890(4)$ \\
\hline$\gamma\left({ }^{\circ}\right)$ & $85.161(5)$ & $107.188(5)$ \\
\hline$V\left(\AA^{3}\right)$ & $1359.7(11)$ & $2366.2(2)$ \\
\hline$Z$ & 2 & 2 \\
\hline$\rho_{\text {calc }}\left(\mathrm{g} \mathrm{cm}^{-3}\right)$ & 1.474 & 1.272 \\
\hline Radiation, $\lambda(\AA)$ & 0.71073 & 1.54184 \\
\hline$\mu\left(\mathrm{mm}^{-1}\right)$ & 1.048 & 2.568 \\
\hline Temperature (K) & $100(2)$ & $100(2)$ \\
\hline Measd/independent reflns $\left(R_{\text {int }}\right)$ & $9180 / 4779(0.0304)$ & $14960 / 8430(0.0311)$ \\
\hline Parameters refined & 334 & 526 \\
\hline GoF (on $F^{2}$ ) & 1.115 & 1.016 \\
\hline$R_{1}^{a}(I>2 \sigma(I))$ & 0.0700 & 0.0448 \\
\hline${ }_{W R_{2}}^{b}(I>2 \sigma(I))$ & 0.1921 & 0.1190 \\
\hline$(\Delta \rho)_{\max } /(\Delta \rho)_{\min }\left(\mathrm{e}^{-3}\right)$ & $1.853 /-0.514$ & $0.769 /-0.364$ \\
\hline$R_{1}=\Sigma\left(\left|F_{\mathrm{O}}\right|-\left|F_{\mathrm{C}}\right|\right) / \Sigma\left(\left|F_{\mathrm{O}}\right|\right)$ & & \\
\hline
\end{tabular}




\section{Table 2}

Selected bond lengths (in $\AA$ ) and angles (degrees) for complexes 1, 2, 3, 3.

\begin{tabular}{|c|c|c|c|c|}
\hline Bond ${ }^{a} /$ Compound & $\mathbf{1}^{(51)}$ & 2 & $3^{(49)}$ & $3^{-}$ \\
\hline $\mathrm{Ni1}-\mathrm{S} 1$ & 2.1209 & $2.130(2)$ & $2.1222(6)$ & $2.1416(5)$ \\
\hline $\mathrm{Ni1}-\mathrm{S} 2$ & 2.1227 & $2.129(2)$ & $2.1217(6)$ & $2.1292(6)$ \\
\hline Ni1 - S3 & 2.1209 & $2.128(2)$ & $2.1341(6)$ & $2.1510(5)$ \\
\hline Ni1 - S4 & 2.1227 & $2.115(2)$ & $2.1182(6)$ & $2.1358(6)$ \\
\hline $\mathrm{C} 1-\mathrm{S} 1$ & 1.716 & $1.699(6)$ & $1.717(2)$ & $1.744(2)$ \\
\hline $\mathrm{C} 2-\mathrm{S} 2$ & 1.703 & $1.711(6)$ & $1.703(2)$ & $1.742(2)$ \\
\hline $\mathrm{C} 16-\mathrm{S} 3$ & 1.716 & $1.707(6)$ & $1.717(2)$ & $1.745(2)$ \\
\hline $\mathrm{C} 17-\mathrm{S} 4$ & 1.703 & $1.714(7)$ & $1.710(2)$ & $1.743(3)$ \\
\hline $\mathrm{C} 1-\mathrm{C} 2$ & $1.388(3)$ & $1.423(8)$ & $1.394(3)$ & $1.368(3)$ \\
\hline $\mathrm{C} 16-\mathrm{C} 17$ & $1.388(3)$ & $1.402(9)$ & $1.391(3)$ & $1.362(2)$ \\
\hline S1-Ni1-S2 & $90.85^{\circ}$ & $91.17(7)^{\circ}$ & $90.91(2)$ & $90.78(2)^{\circ}$ \\
\hline S3-Ni1-S4 & $90.88^{\circ}$ & $91.14(7)^{\circ}$ & $91.25(2)$ & $90.85(2)^{\circ}$ \\
\hline
\end{tabular}

${ }^{a}$ for the sake of comparison, numbering for 3 is in accordance with 2, i.e. bond in 2/bond in 3. Ni1-S2 / Ni1-S2', Ni1-S3 / Ni1-S1', Ni-S4 / Ni-S2, C2-S2 / C2-S2', C16-S3 / C1'-S1', C17-S4 / C2'-S2, C16-C17 / C1'-C2', S1-Ni1-S2 / S1-Ni1-S2', S3-Ni1-S4 / S2-Ni1-S1' 
Table 3

Reduction potentials for complexes $\mathbf{1 ,} 2$ and $\mathbf{3}$.

\begin{tabular}{lcc}
\hline & \multicolumn{2}{c}{$\boldsymbol{E}$ vs Fc } \\
\cline { 2 - 3 } Compound & neutral/monoanion & monoanion/dianion \\
\hline 1 & -0.274 & -1.260 \\
2 & -0.319 & -1.289 \\
3 & -0.370 & -1.325 \\
\hline
\end{tabular}


Table 4

Bulk electrolysis results for complexes 1, 2 and $\mathbf{3}$ in DMF in the presence of $50 \mathrm{mM}$ trifluoroacetic acid.

\begin{tabular}{lcc}
\hline Compound & TON & Faradaic yield $\boldsymbol{a}$ \\
\hline 1 & 15 & 0.66 \\
2 & 25 & 0.83 \\
3 & 12 & 0.74 \\
$2^{b}$ & 47 & 0.23 \\
\hline
\end{tabular}

abulk electrolysis was performed at $-1.67 \mathrm{~V}$ vs $\mathrm{Fc}^{+/ 0}$, for a $3 \mathrm{~h}$ period, catalyst concentration $1 \mathrm{mM}$

$b_{\text {catalyst concentration was } 0.1 \mathrm{mM}}$ 
Table 5

Selected structural parameters calculated for intermediates of the hydrogen evolution mechanism for catalyst 1.

\begin{tabular}{|c|c|c|c|c|c|c|c|}
\hline Parameter ${ }^{a}$ & {$[1]^{47}$} & {$\left[1^{-}\right]$} & {$[1]^{2-}$} & {$[1(\mathrm{~S}-\mathrm{H})]^{-}$} & {$[\mathbf{1}(\mathrm{S}-\mathrm{H})]^{2-}$} & [1(SH-SH)] & {$[\mathbf{1}(\mathbf{S H}-\mathbf{S H})]^{-}$} \\
\hline $\mathrm{Ni1}-\mathrm{S} 1$ & 2.160 & 2.184 & 2.222 & 2.227 & 2.404 & 2.230 & 2.369 \\
\hline Ni1 - S2 & 2.161 & 2.183 & 2.213 & 2.237 & 2.374 & 2.200 & 2.310 \\
\hline $\mathrm{Ni} 1-\mathrm{S} 3$ & 2.160 & 2.185 & 2.219 & 2.185 & 2.312 & 2.205 & 2.335 \\
\hline $\mathrm{Ni1}-\mathrm{S} 4$ & 2.161 & 2.186 & 2.219 & 2.203 & 2.311 & 2.236 & 2.335 \\
\hline $\mathrm{C} 1-\mathrm{S} 1$ & 1.722 & 1.757 & 1.790 & 1.803 & 1.804 & 1.806 & 1.805 \\
\hline $\mathrm{C} 2-\mathrm{S} 2$ & 1.721 & 1.755 & 1.778 & 1.770 & 1.769 & 1.769 & 1.765 \\
\hline $\mathrm{C} 16-\mathrm{S} 3$ & 1.722 & 1.758 & 1.783 & 1.782 & 1.777 & 1.771 & 1.772 \\
\hline $\mathrm{C} 17-\mathrm{S} 4$ & 1.721 & 1.755 & 1.763 & 1.783 & 1.787 & 1.805 & 1.804 \\
\hline $\mathrm{C} 1-\mathrm{C} 2$ & 1.392 & 1.364 & 1.356 & 1.351 & 1.360 & 1.348 & 1.359 \\
\hline $\mathrm{C} 16-\mathrm{C} 17$ & 1.392 & 1.364 & 1.353 & 1.350 & 1.361 & 1.349 & 1.360 \\
\hline $\mathrm{S} 1-\mathrm{H}$ & - & - & - & 1.352 & 1.351 & 1.353 & 1.352 \\
\hline $\mathrm{S} 4-\mathrm{H}$ & & & & & & 1.352 & 1.352 \\
\hline S-Ni-S dihedral angle & 0 & 0 & $0.8^{\circ}$ & $2.32^{\circ}$ & $20.44^{\circ}$ & $8.87^{\circ}$ & $39.93^{\circ}$ \\
\hline
\end{tabular}

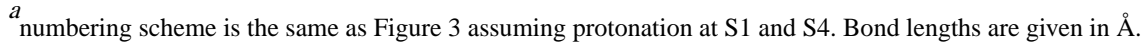

